Research Article

\title{
Improvement in the Flux Uniformity of the Solar Dish Concentrator System through a Concave Quartz Window
}

\author{
Du-zhong Nie $\mathbb{D}^{1,2}$ You-duo Peng $\mathbb{D}^{1},{ }^{1}$ Jian Yan $\mathbb{D}^{1},{ }^{1}$ Cheng-ji Mi, ${ }^{3}$ Yong-xiang Liu, ${ }^{1}$ \\ and Yong Tian ${ }^{1}$ \\ ${ }^{1}$ School of Mechanical Engineering, Hunan University of Science and Technology, Xiangtan, Hunan 411201, China \\ ${ }^{2}$ Institute of Intelligent Equipment Technology, Hunan Vocational College of Science and Technology, Changsha, \\ Hunan 410004, China \\ ${ }^{3}$ Department of Mechanical Engineering, Hunan University of Technology, Zhuzhou, Hunan 412007, China
}

Correspondence should be addressed to You-duo Peng; ydpeng@hnust.edu.cn and Jian Yan; yanjiancaoyue@163.com

Received 16 January 2020; Revised 9 March 2020; Accepted 14 March 2020; Published 9 April 2020

Academic Editor: Leonardo Palmisano

Copyright (C) 2020 Du-zhong Nie et al. This is an open access article distributed under the Creative Commons Attribution License, which permits unrestricted use, distribution, and reproduction in any medium, provided the original work is properly cited.

A nonuniform and high-strength heat flux load would reduce the working efficiency, safety, and in-service life of a cavity receiver Four types of concave quartz windows, including conical, spherical, sinusoidal, and hyperbolic tangent, were proposed to be used in the cylindrical cavity receiver of a solar dish concentrator system, which can improve the flux uniformity and reduce the peak concentration ratio of the receiver. For each concave quartz window, 36 structural schemes were offered. Based on the Monte Carlo ray-tracing method, the results showed that the nonuniformity coefficient of the receiver was 0.68 and the peak concentration ratio was 1320.21 by using a plane quartz window. At the same time, when the receiver is in the best optical performance, it is the receiver with sinusoidal, conical, spherical, and hyperbolic tangent quartz windows, respectively. The optical efficiency of the receiver with the above four types of quartz windows was basically the same as that of the receiver with the plane quartz window, but their nonuniformity coefficients were reduced to $0.31,0.35,0.36$, and 0.39 , respectively, and the peak concentration ratio was reduced to $806.82,841.31,853.23$, and 875.89 , respectively. Obviously, the concave quartz window was better than the plane quartz window in improving the flux uniformity. Finally, a further study on the sinusoidal quartz window scheme of all of the above optimal parameter schemes showed that when the installation position of the receiver relative to the dish concentrator was changed, the flux uniformity of the receiver could continue to improve. When the surface absorptivity of the receiver was reduced, the optical efficiency would be reduced. For the parabolic dish concentrator with different focal distance, the concave quartz window can also improve the uniformity of the flux distribution of the cylindrical cavity receiver.

\section{Introduction}

Solar energy is a clean and environmentally friendly renewable energy. Due to the low density of solar radiation received by the earth's surface, a solar concentrator is an indispensable core device in a solar energy high-grade utilization system. It can obtain high-density solar radiation on a small area of receivers to improve the energy utilization efficiency or reduce the construction cost $[1,2]$. A solar dish concentrator/cavity receiver system (SDCR) is a typical high-grade concentrating and heat collecting device that is widely used in the field of solar thermal utilization [3]. However, the flux distribution of the cavity receiver is highly uneven [4], which results in a high temperature gradient on the inner wall of the receiver, a reduction in the working efficiency of the receiver, and, even more seriously, burning of key components such as the heat exchanger $[5,6]$.

To improve the flux uniformity of the cavity receiver, the following work has been conducted. Chong et al. $[7,8]$ proposed a nonimaging planar concentrator and a design method to obtain a uniform flux distribution on a planar receiver. Yan et al. [9] proposed a mirror rearranging method for a parabolic dish concentrator and a novel discrete dish concentrator [10], which significantly improved the flux 


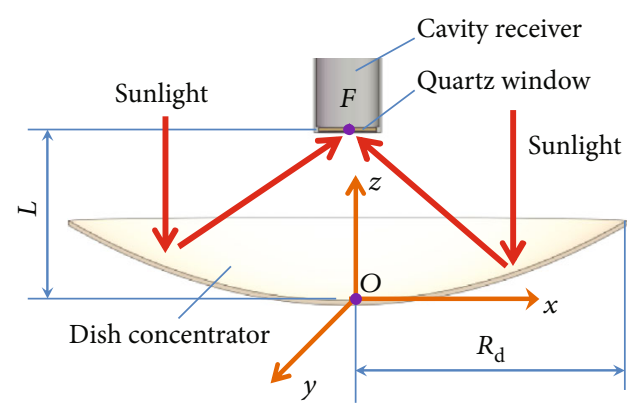

(a)

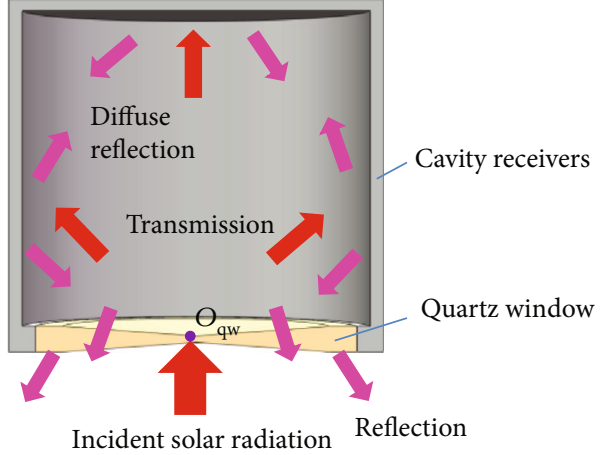

(b)

FIGURE 1: SDCR system. (a) Geometric parameters and working principle of the SDCR system. (b) Solar radiation transport of the cavity receiver.

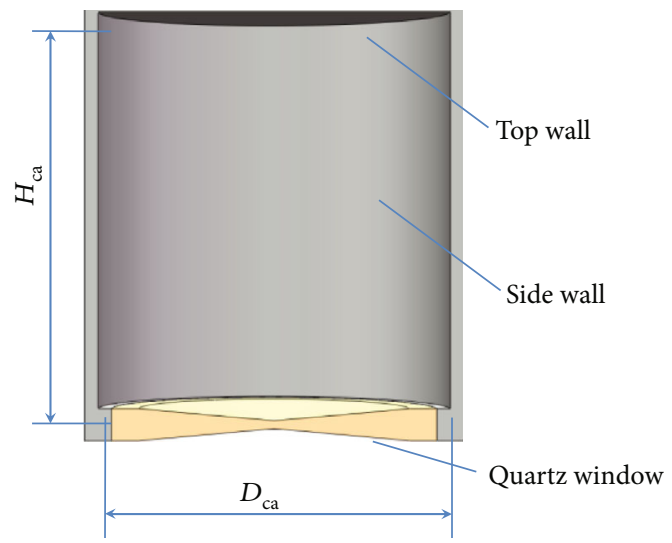

(a)

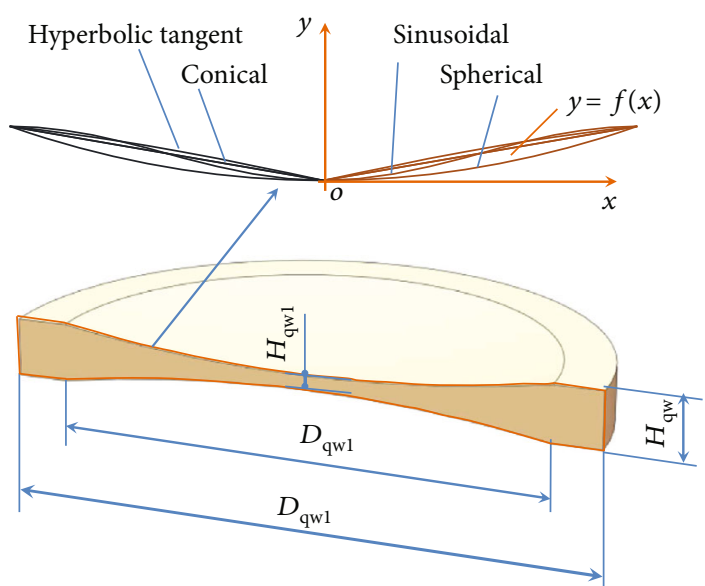

(b)

Figure 2: (a) Cylindrical cavity receiver with quartz window. (b) Structure of quartz window.

uniformity of the cavity receiver. Evangelos et al. [11] proposed cylindrical, rectangular, spherical, conical, and cylindrical-conical receivers, and the research shows that the cylindrical-conical receiver has the best flux uniformity. Shuai et al. [12] designed a pear-like cavity receiver, which has better flux uniformity than a hemispherical receiver. Jin et al. [13] proposed to add carbon particles in the boiling tube of the receiver, and Tao et al. [14] studied the use of phasechange materials in the cavity receiver, which can improve the uniformity of the temperature distribution on the heat exchange surface of the receiver. In addition, to enable a large amount of heat exchange and chemical reactions to be conducted in the cavity receiver $[15,16]$, the key condition for the receiver to form a closed high-pressure space [17] is installing a quartz window, which can make the solar radiation pass through at the front end of the receiver. Currently, the quartz windows that have been successfully applied are mainly planar $[18,19]$, hemispherical $[20,21]$, and semielliptical quartz windows [22] with equal thickness. Shuai et al. [23] designed a planoconvexo quartz window on a cavity receiver. The research showed that the redistribution effect of the convex quartz window on the solar radiation can
TABLE 1: The values of $\mathrm{D}_{\mathrm{qw}}$ and $\mathrm{H}_{\mathrm{qw}}$ of the concave quartz window.

\begin{tabular}{lllllll}
\hline $\mathrm{H}_{\mathrm{qw}}, \mathrm{mm}$ & \multicolumn{5}{c}{$\mathrm{D}_{\mathrm{qw}}, \mathrm{mm}$} \\
\hline 18 & 140 & 160 & 180 & 200 & 220 & 240 \\
20 & 140 & 160 & 180 & 200 & 220 & 240 \\
22 & 140 & 160 & 180 & 200 & 220 & 240 \\
24 & 140 & 160 & 180 & 200 & 220 & 240 \\
26 & 140 & 160 & 180 & 200 & 220 & 240 \\
28 & 140 & 160 & 180 & 200 & 220 & 240 \\
\hline
\end{tabular}

also improve the uniformity of the flux distribution on the receiver surface, but their research did not involve the detailed influence of the concave quartz window on the flux distribution of the receiver.

A previous literature review has shown that people have a strong interest in the flux uniformity of the solar cavity receiver; however, the research on how to improve the flux uniformity of the receiver by redistributing the solar radiation on the receiver through the concave quartz window is not very in-depth. Therefore, it is of great practical significance to study the concave quartz windows of various structures to 


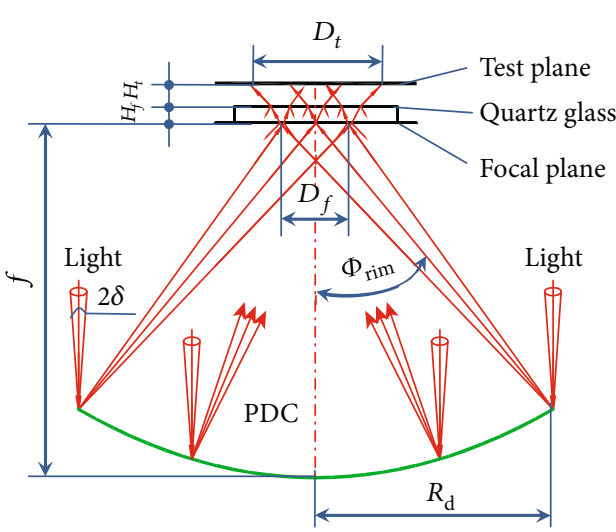

(a)

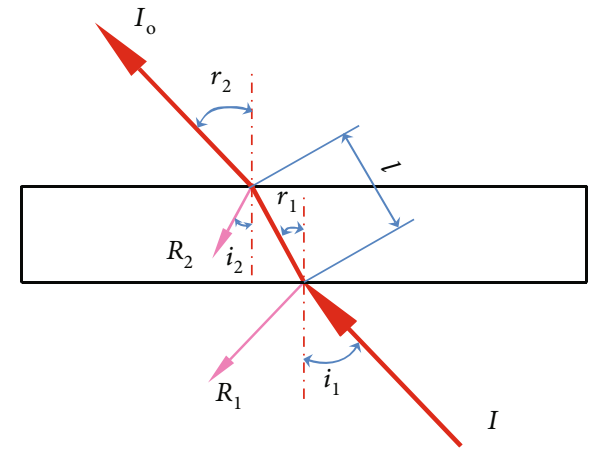

(b)

Figure 3: (a) Improved Jeter's model. (b) Transmission route of solar radiation through a quartz window.

TABLE 2: Summary of the validation model.

\begin{tabular}{|c|c|c|}
\hline Parameter & Symbol & Value \\
\hline Thickness of the quartz window & $\mathrm{H}_{f}$ & $6 \mathrm{~mm}$ \\
\hline $\begin{array}{l}\text { Distance between the receiving plane for the } \\
\text { test and quartz window }\end{array}$ & $\mathrm{H}_{t}$ & $1.8 \mathrm{~mm}$ \\
\hline Wavelength of the solar radiation & $\lambda$ & $587 \mathrm{~nm}$ \\
\hline Absorption coefficient of the quartz window & $\mathrm{k}_{\lambda}$ & $1.4 \mathrm{~m}^{-1}$ \\
\hline Refractive index of the quartz window & $\mathrm{n}$ & 1.5 \\
\hline Reflectivity of the quartz window & $\rho_{\mathrm{qw}}$ & 0.04 \\
\hline
\end{tabular}

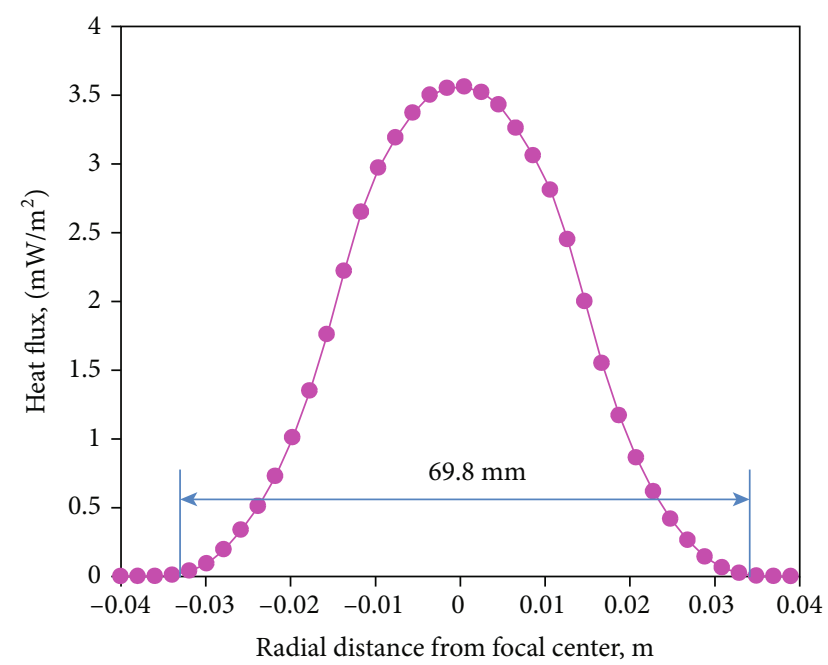

FIgURE 4: Flux distribution of test plane.

improve the flux uniformity of the cavity receiver. In this paper, four typical concave quartz windows, including sinusoidal, conical, spherical, and hyperbolic tangent, are proposed to improve the flux uniformity of the cylindrical cavity receiver in the dish concentrator system. By analyzing the optical efficiency, the local concentration ratio, the nonuniformity coefficient and the peak concentration ratio of the cavity receiver with a concave quartz window, the flux distribution of the
TABLE 3: Summary of the SDCR system.

\begin{tabular}{|c|c|c|}
\hline Parameter & Symbol & Value \\
\hline Aperture radius of the dish concentrator & $\mathrm{R}_{d}$ & $8.85 \mathrm{~m}$ \\
\hline Focal length of the dish concentrator & $f$ & $9.49 \mathrm{~m}$ \\
\hline Reflectivity of the dish concentrator surface & $\rho_{\mathrm{d}}$ & 0.92 \\
\hline $\begin{array}{l}\text { Absorptivity of the dish concentrator } \\
\text { surface }\end{array}$ & $\sigma_{\mathrm{d}}$ & 0.08 \\
\hline Absorptivity of the cavity receiver surface & $\sigma_{\mathrm{ca}}$ & 0.95 \\
\hline Reflectivity of the cavity receiver surface & $\rho_{\mathrm{ca}}$ & 0.05 \\
\hline $\begin{array}{l}\text { The value of the solar direct normal } \\
\text { irradiance }\end{array}$ & $\mathrm{W}_{0}$ & $1000 \mathrm{~W} / \mathrm{m}^{2}$ \\
\hline Rim angle of the dish concentrator & $\delta$ & $4.65 \mathrm{mrad}$ \\
\hline
\end{tabular}

TABLE 4: Optical properties of quartz glass.

\begin{tabular}{lccc}
\hline$\lambda$, um & $\mathrm{n}$ & $\rho_{q w}$ & $\mathrm{k}_{\lambda}, \mathrm{m}^{-1}$ \\
\hline $0.2-2.7$ & 1.51 & 0.04 & 1.4 \\
$2.7-\infty$ & 1.48 & 0.04 & 1000 \\
\hline
\end{tabular}

receiver with a concave quartz window, and a planar quartz window were compared with each other, and the receivers with different concave quartz windows were compared as well. Finally, the influence of the installation position of the receiver and the absorptivity of the cavity receiver surface on the flux distribution of the receiver is discussed.

\section{Model Description}

In this paper, the solar dish concentrator/cavity receiver system (SDCR) was taken as the research object, as shown in Figure 1(a). This system is composed of a parabolic dish concentrator and a cylindrical cavity receiver with a quartz window. The equation of the disc concentrator can be expressed as $\mathrm{x}^{2}+\mathrm{y}^{2}=4 \mathrm{fz}$, in which the focal length of the dish concentrator is $f$, the aperture radius of the dish concentrator is $\mathrm{R}_{\mathrm{d}}$, and the distance between the dish concentrator and the 


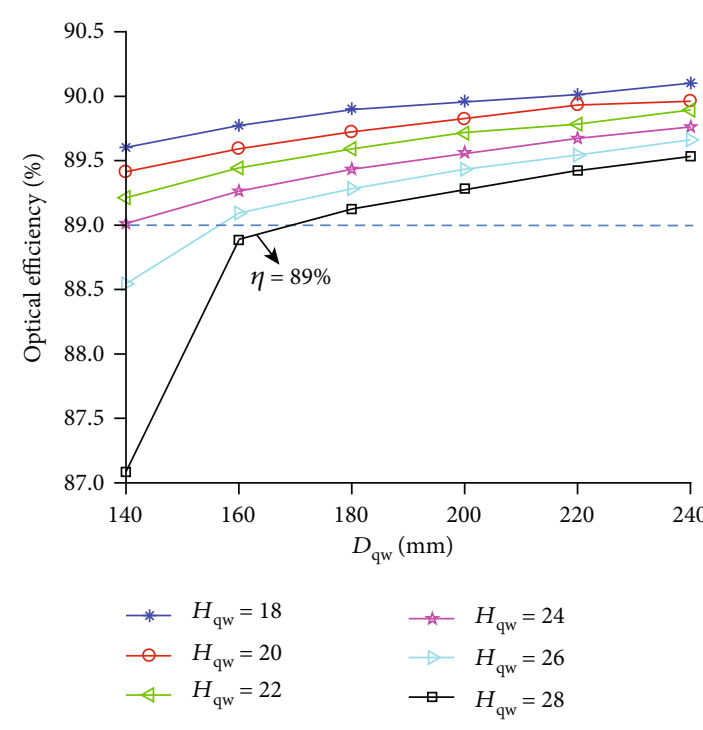

(a)

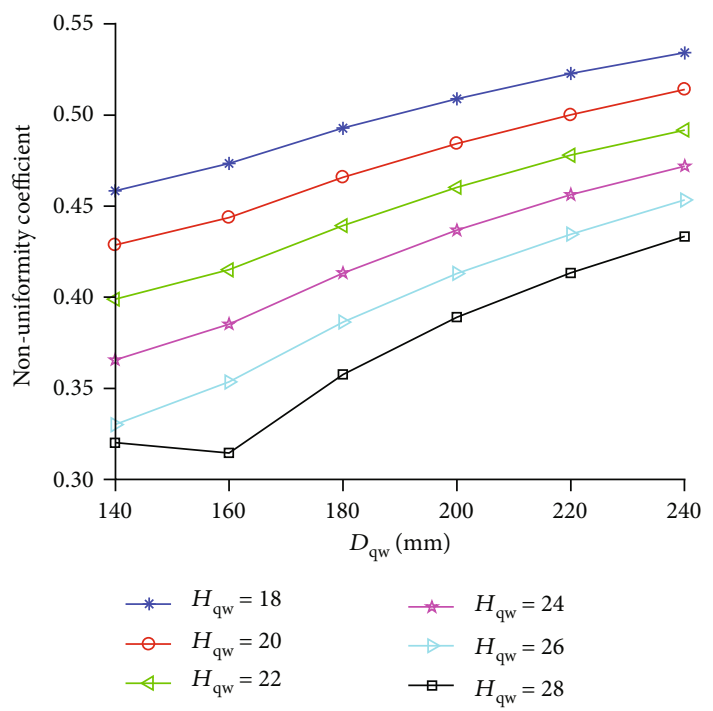

(c)

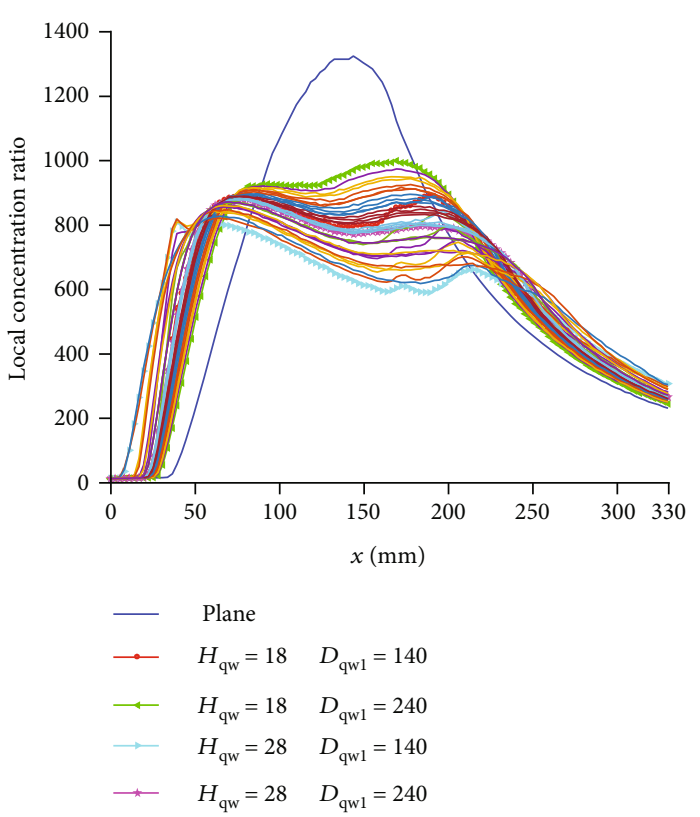

(b)

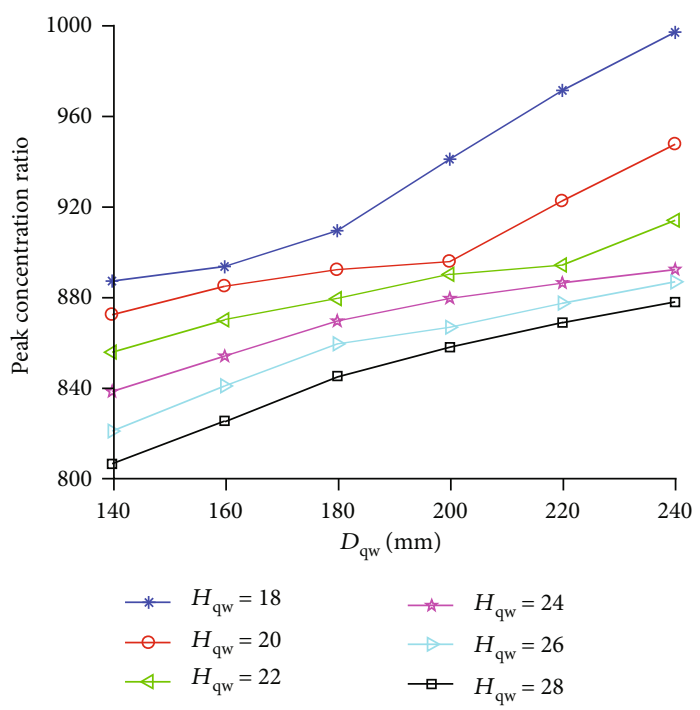

(d)

FIGURE 5: Optical performance of the cylindrical cavity receiver with a conical quartz window. (a) Optical efficiency. (b) LCR. (c) Nonuniformity coefficient. (d) PCR.

receiver is $L$. As shown in Figure 1, the quartz window is installed at the solar radiation entrance of the cylindrical cavity receiver. The central point of the quartz window is $O_{\mathrm{qw}}$. When the focus point $F$ of the dish concentrator coincides with $O_{\mathrm{qw}}$, the distance between the dish concentrator and the receiver $L$ is equal to the focal length of the dish concentrator, $f$. In the SDCR system, most of the solar radiation gathered by the dish concentrator enters the inner surface of the receiver through the quartz window, and some of the radiation is absorbed by the quartz window or reflected into the atmosphere through the quartz window, while some of the solar radiation that enters the receiver cavity will diffuse and then escape through the quartz window. To improve the flux uniformity of the cavity receiver, four typical concave quartz windows were proposed in this paper, which were conical, spherical, sinusoidal, and hyperbolic tangent.

Figure 2(a) describes that the absorption surface of the cylindrical cavity receiver is $D_{\text {ca }}$ in diameter and $H_{c a}$ in height. Figure 2(b) describes that the upper and lower surface of the quartz window are composed of symmetrical concave surfaces. In this paper, four types of quartz windows, including conical, spherical, sinusoidal and hyperbolic, are included. The center thickness of the quartz window is $H_{\mathrm{qw1}}$, the edge thickness is $H_{\mathrm{qw}}$, the outside diameter is $D_{\mathrm{qwl}}$, and the diameter of the concave surface is $D_{\mathrm{qw}}$. The contour curves of four types of concave sections in the first 
TABLE 5: Optical performance of the cylindrical cavity receiver with a conical quartz window.

\begin{tabular}{|c|c|c|c|c|c|c|c|}
\hline \multirow{2}{*}{$\mathrm{H}_{\mathrm{qw}}, \mathrm{mm}$} & \multirow{2}{*}{ Parameters } & \multicolumn{6}{|c|}{$\mathrm{D}_{\mathrm{qw}}, \mathrm{mm}$} \\
\hline & & 140 & 160 & 180 & 200 & 220 & 240 \\
\hline \multirow{3}{*}{18} & $\eta(\%)$ & 89.60 & 89.77 & 89.90 & 89.96 & 90.01 & 90.10 \\
\hline & PCR & 887.64 & 894.03 & 909.89 & 941.54 & 971.94 & 997.68 \\
\hline & $\mathrm{V}_{\sigma}$ & 0.46 & 0.47 & 0.49 & 0.51 & 0.52 & 0.53 \\
\hline \multirow{3}{*}{20} & $\eta(\%)$ & 89.41 & 89.59 & 89.72 & 89.82 & 89.93 & 89.96 \\
\hline & PCR & 872.76 & 885.35 & 892.65 & 896.25 & 923.06 & 948.15 \\
\hline & $\mathrm{V}_{\sigma}$ & 0.43 & 0.44 & 0.47 & 0.48 & 0.50 & 0.51 \\
\hline \multirow{3}{*}{22} & $\eta(\%)$ & 89.21 & 89.44 & 89.59 & 89.71 & 89.78 & 89.89 \\
\hline & PCR & 856.22 & 870.52 & 879.89 & 890.62 & 894.74 & 914.51 \\
\hline & $\mathrm{V}_{\sigma}$ & 0.40 & 0.42 & 0.44 & 0.46 & 0.48 & 0.49 \\
\hline \multirow{3}{*}{24} & $\eta(\%)$ & 89.01 & 89.26 & 89.43 & 89.56 & 89.67 & 89.76 \\
\hline & PCR & 838.80 & 854.42 & 869.97 & 880.01 & 886.83 & 892.79 \\
\hline & $\mathrm{V}_{\sigma}$ & 0.37 & 0.39 & 0.41 & 0.44 & 0.46 & 0.47 \\
\hline \multirow{3}{*}{26} & $\eta(\%)$ & 88.54 & 89.09 & 89.28 & 89.43 & 89.54 & 89.66 \\
\hline & PCR & 821.33 & 841.31 & 859.92 & 867.25 & 877.88 & 887.27 \\
\hline & $\mathrm{V}_{\sigma}$ & 0.33 & 0.35 & 0.39 & 0.41 & 0.43 & 0.45 \\
\hline \multirow{3}{*}{28} & $\eta(\%)$ & 87.08 & 88.88 & 89.12 & 89.28 & 89.42 & 89.53 \\
\hline & PCR & 806.83 & 825.80 & 845.64 & 858.37 & 869.27 & 878.43 \\
\hline & $\mathrm{V}_{\sigma}$ & 0.32 & 0.31 & 0.36 & 0.39 & 0.41 & 0.43 \\
\hline
\end{tabular}

quadrant are represented by the following equations in the coordinate system of the diagram.

$$
\begin{aligned}
& \text { Conical contour curves : } \mathrm{f}(x)=k x\left(\frac{0 \leq \mathrm{x} \leq D_{\mathrm{qw}}}{2}\right), \quad, \\
& \text { Spherical contour curves : } \mathrm{f}(x)=\mathrm{t}-\sqrt{\mathrm{t}^{2}-x^{2}}\left(\frac{0 \leq \mathrm{x} \leq D_{\mathrm{qw}}}{2}\right),
\end{aligned}
$$

Sinusoidal contour curves : $\mathrm{f}(x)=\mathrm{A}+\mathrm{A} \cdot \sin (k x-0.5 \pi)$

$$
\left(\frac{0 \leq \mathrm{x} \leq D_{\mathrm{qw}}}{2}\right)
$$

$$
\begin{aligned}
& \text { Hyperbolic tangent contour curves : } \mathrm{f}(x)=\mathrm{A}\left(\frac{\mathrm{e}^{k x}-e^{-k x}}{e^{k x}+e^{-k x}}\right) \\
& \left(\frac{0 \leq \mathrm{x} \leq D_{\mathrm{qw}}}{2}\right) \text {. }
\end{aligned}
$$

Here, $k, t$, and $A$ are the parameters of the equation that must be given fixed values.

When $x$ is in the range of 0 to $D_{\mathrm{qw}} / 2$, according to the above contour curve equation, it can be concluded that the slope of the conical contour curve remains constant with any increases in the $x$ value, while the slope of the spherical contour curve increases, and the slope of the sinusoidal contour curve increases first and then decreases. However, the slope of the hyperbolic tangent contour curve decreases, and the above four slope values are all positive. Therefore, the selection of these four concave quartz windows is very representative.

In the specific case studied in this paper, the structure parameter $\mathrm{D}_{\mathrm{ca}}$ of the receiver is $260 \mathrm{~mm}$, and the height $\mathrm{H}_{\mathrm{ca}}$ is $330 \mathrm{~mm}$. Among the four concave quartz windows in this study, the structural parameter $\mathrm{H}_{\mathrm{qw} 1}$ is taken to be $6 \mathrm{~mm}$, and the outside diameter $\mathrm{D}_{\mathrm{qw} 1}$ is $240 \mathrm{~mm}$. $\mathrm{H}_{\mathrm{qw}}$ and $\mathrm{D}_{\mathrm{qw}}$ had 6 sets of values, as shown in Table 1. The contour curve of the concave quartz window is determined by Equations (1)-(4), in such a way that 36 different structural schemes of the concave quartz window are formed.

\section{Methodology and Model Validation}

3.1. Methodology. In this paper, the optical software OptisWorks, which is based on the Monte Carlo ray-tracing method (MCRT), is used for analysis. This software has been widely used in optical analysis, and it can be reliable. For example, Daabo et al. [24] and Yan et al. [25] in our research group used OptisWorks based on MCRT to systematically study the optical performance of a cavity receiver.

To evaluate the influence of a concave quartz window on the optical performance of a cavity receiver, it is usually necessary to evaluate the performances of the receiver, including the optical efficiency, local concentration ratio (LCR), and nonuniformity coefficient used to characterize the uniformity of the flux distribution.

The optical efficiency $\eta$ of the receiver can be calculated according to Equation (5), where $E_{\mathrm{ca}}$ is the total energy absorbed by the cylindrical cavity receiver, $W_{0}$ is the value 

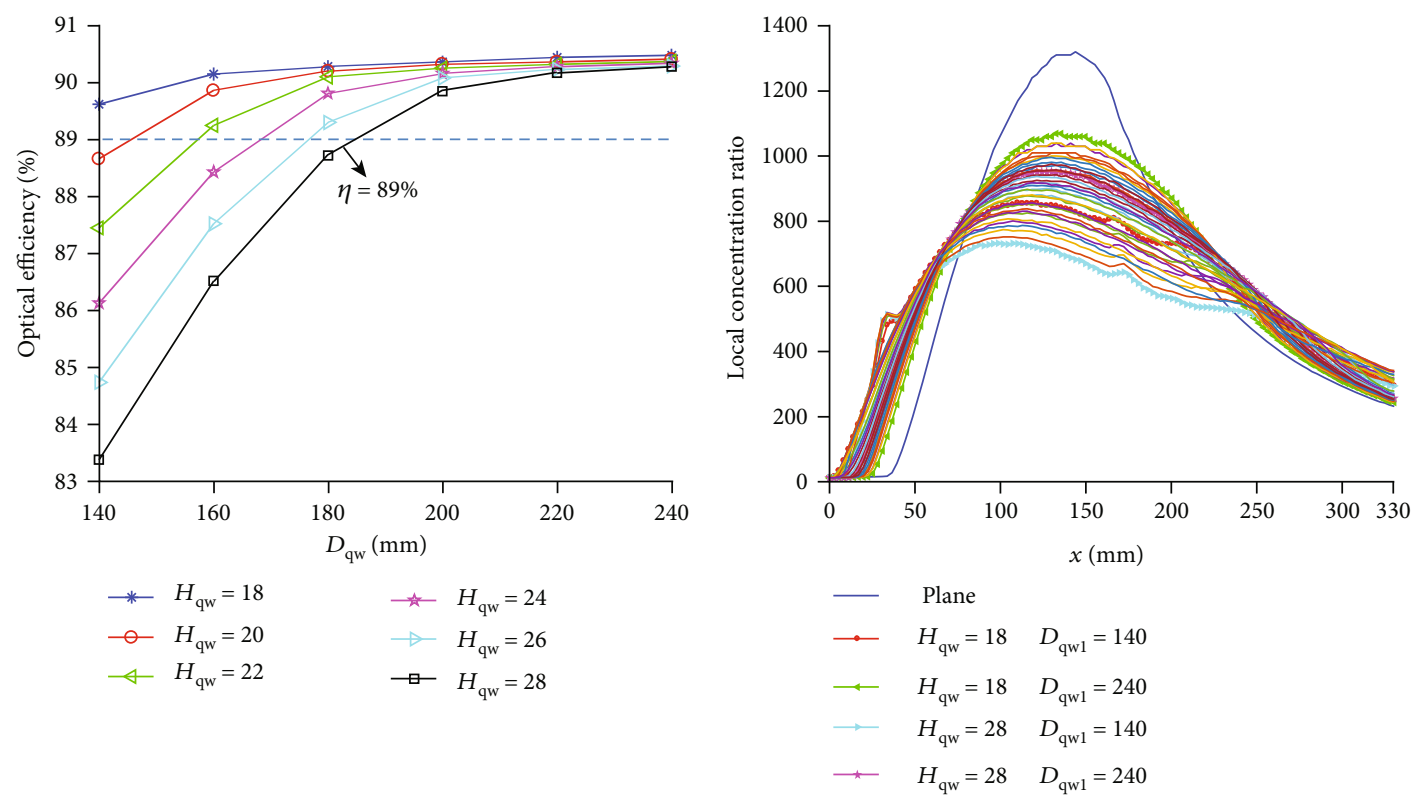

(a)

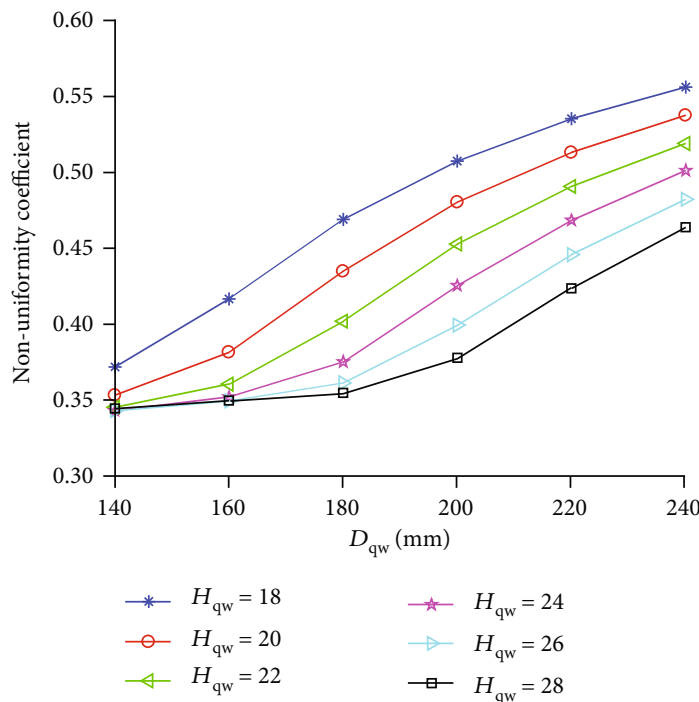

(c)

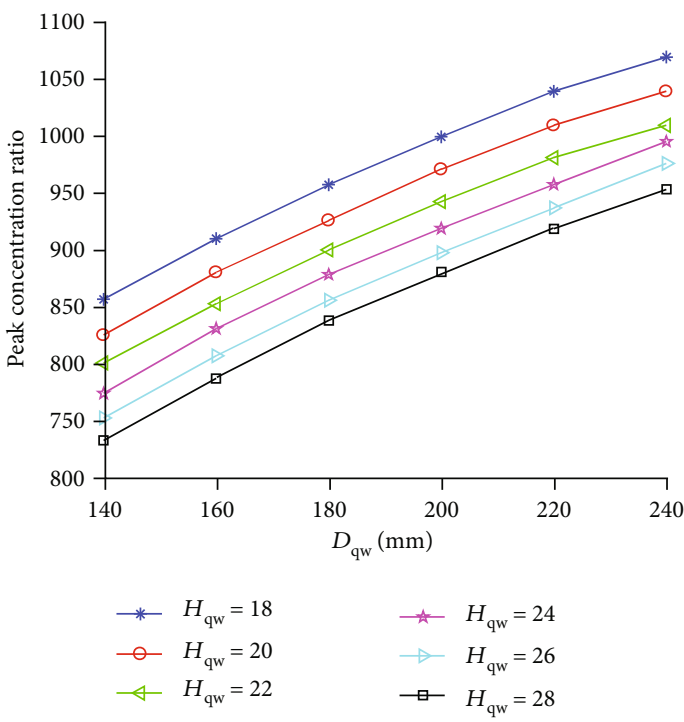

(d)

FIgURE 6: Optical performance of the cylindrical cavity receiver with the spherical quartz window. (a) Optical efficiency. (b) LCR. (c) Nonuniformity coefficient. (d) PCR.

of the solar direct normal irradiance, and $\rho_{\mathrm{d}}$ is the reflectivity of the dish concentrator surface:

$$
\eta=\frac{E_{\mathrm{ca}}}{\pi R_{\mathrm{d}}^{2} \cdot W_{\boldsymbol{0}} \cdot \rho_{\mathrm{d}}} \cdot 100 \% .
$$

The cavity receiver usually uses the nonuniform coefficient $V_{\sigma}$ to characterize the uniformity of its flux distribution, which can be calculated by Equation (6) [26]. In this paper, in the process of calculating the flux distribution of the receiver with the OptisWorks software, the solar radiation-receiving surface of the receiver will be meshed, where $\mathrm{E}_{i}$ is the flux distribution value received in the $i$ th grid area and $E_{\text {average }}$ is the average value of the flux distribution of the cavity receiver:

$$
V_{\sigma}=\frac{\sqrt{\sum_{i=1}^{n}\left(\mathrm{E}_{i}-E_{\text {average }}\right)^{2} /(\mathrm{n}-1)}}{E_{\text {average }}} .
$$

Then, the value of the local concentration ratio $C_{i}$ can be expressed as in Equation (7), where $A_{i}$ is the area of the $i$ th grid area:

$$
\mathrm{C}_{\mathrm{i}}=\frac{\mathrm{E}_{i}}{\mathrm{~A}_{\mathrm{i}} \cdot \mathrm{W}_{0}}
$$


TABLE 6: Optical performance of the cylindrical cavity receiver with a spherical quartz window.

\begin{tabular}{cccccccc}
\hline \multirow{2}{*}{$\mathrm{H}_{\mathrm{qw}}, \mathrm{mm}$} & Parameters & 140 & 160 & 180 & 200 & 220 & 240 \\
\hline \multirow{3}{*}{18} & $\eta(\%)$ & 89.62 & 90.15 & 90.28 & 90.36 & 90.44 & 90.48 \\
& $\mathrm{PCR}$ & 857.19 & 910.50 & 957.90 & 1000.00 & 1040.00 & 1070.00 \\
& $\mathrm{~V}_{\sigma}$ & 0.37 & 0.42 & 0.47 & 0.51 & 0.54 & 0.55 \\
\hline \multirow{2}{*}{20} & $\eta(\%)$ & 88.66 & 89.86 & 90.20 & 90.32 & 90.36 & 90.41 \\
& $\mathrm{PCR}$ & 825.84 & 880.92 & 926.45 & 971.53 & 1010.00 & 1040.00 \\
& $\mathrm{~V}_{\sigma}$ & 0.35 & 0.38 & 0.44 & 0.48 & 0.51 & 0.54 \\
\hline \multirow{4}{*}{22} & $\eta(\%)$ & 87.45 & 89.25 & 90.10 & 90.25 & 90.32 & 90.37 \\
& $\mathrm{PCR}$ & 801.34 & 853.23 & 900.65 & 942.97 & 981.63 & 1010.00 \\
& $\mathrm{~V}_{\sigma}$ & 0.35 & 0.36 & 0.40 & 0.45 & 0.49 & 0.52 \\
\hline \multirow{4}{*}{24} & $\eta(\%)$ & 86.13 & 88.43 & 89.81 & 90.16 & 90.28 & 90.34 \\
& $\mathrm{PCR}$ & 774.57 & 831.48 & 878.94 & 919.50 & 958.04 & 995.78 \\
& $\mathrm{~V}_{\sigma}$ & 0.34 & 0.35 & 0.38 & 0.43 & 0.47 & 0.50 \\
\hline \multirow{2}{*}{26} & $\eta(\%)$ & 84.74 & 87.52 & 89.30 & 90.08 & 90.23 & 90.29 \\
& $\mathrm{PCR}$ & 752.89 & 807.73 & 856.42 & 898.27 & 937.46 & 976.56 \\
& $\mathrm{~V}_{\sigma}$ & 0.34 & 0.35 & 0.36 & 0.40 & 0.45 & 0.48 \\
\hline \multirow{2}{*}{28} & $\eta(\%)$ & 83.38 & 86.52 & 88.72 & 89.85 & 90.17 & 90.28 \\
& $\mathrm{PCR}$ & 733.21 & 787.74 & 838.66 & 881.20 & 919.11 & 953.81 \\
& $\mathrm{~V}_{\sigma}$ & 0.34 & 0.35 & 0.36 & 0.38 & 0.42 & 0.46 \\
\hline
\end{tabular}

3.2. Model Validation. To verify the accuracy of the above methods in this study, the verification of this paper is divided into two steps. The first step is to verify the flux distribution on the focal plane of Jeter's model [25] by using the OptisWorks simulation software based on MCRT. Through the comparison between the results of the OptisWorks simulation and Jeter's calculation [27], it is found that the two methods are highly consistent, and the verification process is shown in the previous work of the same research group [23]; the present paper will not elaborate.

Because the receiver in the SDCR system analyzed in this paper is a cavity receiver with a quartz window, the model with a quartz window must be further verified by the method mentioned above. Therefore, this paper uses the improved Jeter's model for further verification. As shown in Figure 3, an $8 \mathrm{~mm}$ thick quartz window is added above the focal plane of Jeter's verification model, and a test flux receiving plane is set at a distance of $10 \mathrm{~mm}$ from the quartz window. When the solar radiation is directly on the parabolic dish concentrator, the gathered solar radiation will be refracted, reflected, and absorbed when passing through the quartz window. At the same time, because of the symmetry of the model, when the solar radiation reaches the test plane, a circular spot will be formed. At this time, the diameter of the spot and the total energy at the spot calculated by this method are compared with the theoretical results. If the data is highly consistent, then the method is reliable. The parameters in the validation model are shown in Table 2, and the other parameters refer to the Jeter model [27] data.
First, the theoretical calculation of the spot diameter reaching the test plane is conducted, and the parameters of the dish concentrator can be referred to [27].

As shown in Figure 3(a), the spot diameter of Jeter's model is calculated as follows, where $\phi_{\text {rim }}=\arctan \left(4 f \cdot \mathrm{R}_{\mathrm{d}} l\right.$ $\left.4 \mathrm{f}^{2}-R_{\mathrm{d}}{ }^{2}\right)$, and $\delta$ is the solar half angle:

$$
\mathrm{D}_{\mathrm{f}}=\frac{2 \mathrm{R}_{\mathrm{d}}}{\cos \left(\phi_{\text {rim }}+\delta\right)} \times \frac{\sin \delta}{\sin \phi_{\text {rim }}} .
$$

As shown in Figure 3(b), when the incident light enters and exits the quartz window, refraction will occur on the interface surface, and the direction of the refraction follows Snell's law. Because the incident angle of the solar radiation at the limit position of the incident quartz window is $i_{1}=$ $\phi_{\text {rim }}+\delta$, the value of the spot diameter of the test plane can be expressed as follows:

$$
\begin{aligned}
\mathrm{D}_{t}= & D_{f}+2 \mathrm{H}_{\mathrm{f}} \tan \left(\arcsin \frac{\sin \left(\phi_{\text {rim }}+\delta\right)}{n}\right) \\
& +2 \mathrm{H}_{t} \tan \left(\phi_{\text {rim }}+\delta\right) .
\end{aligned}
$$

The above is calculated at $D_{t}=69.8 \mathrm{~mm}$.

Secondly, the total energy that reaches the test plane spot is calculated theoretically, which can be expressed as follows:

$$
E_{\text {focus }}=\pi \cdot R_{\mathrm{d}}^{2} \cdot W_{0} \cdot \rho_{\mathrm{d}}
$$




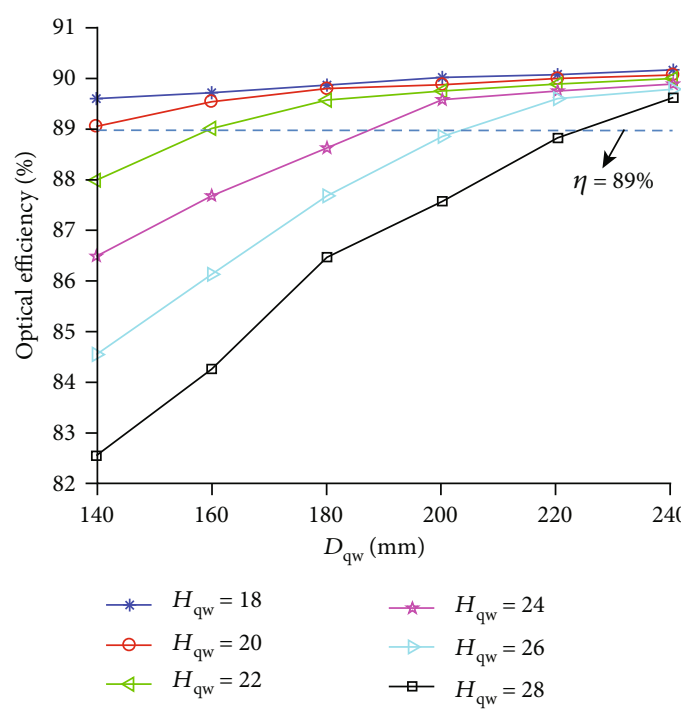

(a)

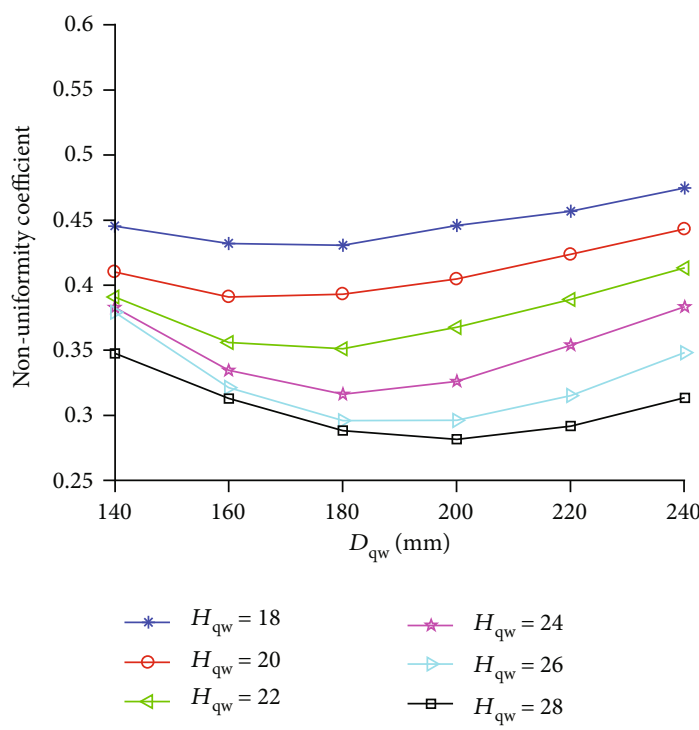

(c)

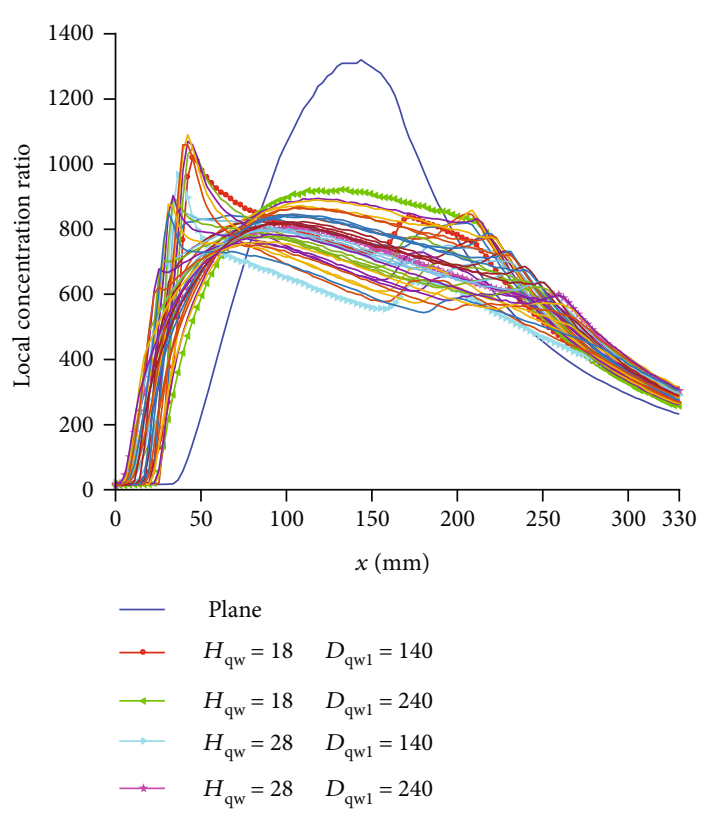

(b)

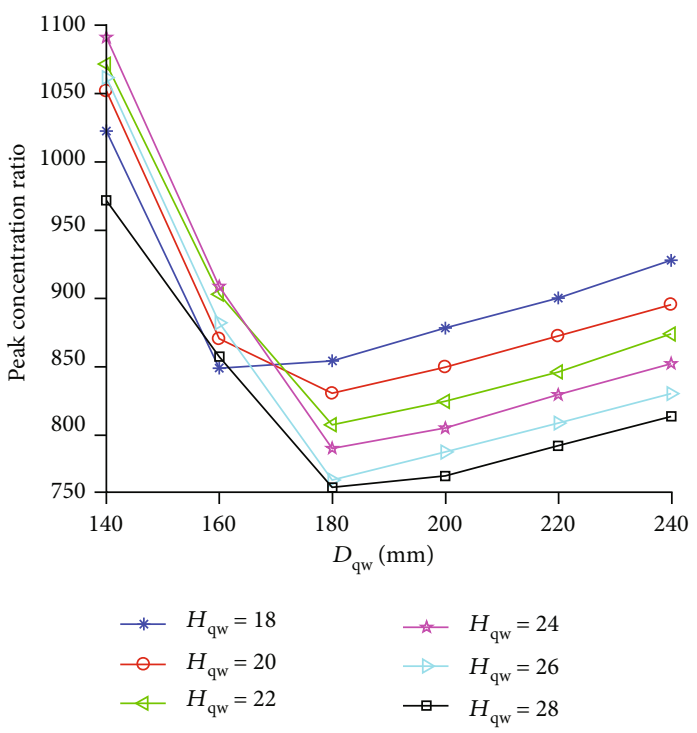

(d)

FIGURE 7: Optical performance of the cylindrical cavity receiver with the sinusoidal quartz window. (a) Optical efficiency. (b) LCR. (c) Nonuniformity coefficient. (d) PCR.

When the solar radiation passes through the quartz window, it will cause a loss of solar radiation due to the reflection and absorption of the quartz window. Then, the total energy $E_{\text {test }}$ transmitted through the quartz window to the test plane can be expressed as follows:

$$
E_{\text {test }}=E_{\text {focus }} \cdot T \text {, }
$$

where the transmissivity of the quartz window is $\mathrm{T}=$ $\left(1-\rho_{q w}\right)^{2} \cdot \mathrm{e}^{-\mathrm{k}_{\lambda} \cdot l}$ [28]. Here, 1 is the distance of the solar radiation passing through the quartz window. In this paper, 1 is the average distance of the light radiation pass- ing through the quartz window, which is calculated as $9.8 \mathrm{~mm}$.

Through Equations (10) and (11), it can be calculated that the total energy in the test plane is $3433 \mathrm{~W}$.

The results of the flux distribution of the focal spot in the test plane are shown in Figure 4 through the simulation calculation with the OptisWorks software. The diameter of the spot is approximately $69.8 \mathrm{~mm}$, which is highly consistent with the theoretical calculation result of Equation (9). The simulation results show that the total energy of the test plane is $3436 \mathrm{~W}$, and the error is $0.09 \%$ compared with the theoretical results of Equation (11), and the two results are very close to each other. To summarize, in this paper, using OptisWorks software for the simulation calculations is reliable. 
TABLE 7: Optical performance of the cylindrical cavity receiver with a sinusoidal quartz window.

\begin{tabular}{|c|c|c|c|c|c|c|c|}
\hline \multirow{2}{*}{$\mathrm{H}_{\mathrm{qw}}, \mathrm{mm}$} & \multirow{2}{*}{ Parameters } & \multicolumn{6}{|c|}{$\mathrm{D}_{\mathrm{qw}}, \mathrm{mm}$} \\
\hline & & 140 & 160 & 180 & 200 & 220 & 240 \\
\hline \multirow{3}{*}{18} & $\eta(\%)$ & 89.62 & 89.74 & 89.89 & 90.04 & 90.10 & 90.19 \\
\hline & PCR & 1020.00 & 842.89 & 848.35 & 872.79 & 895.15 & 923.42 \\
\hline & $\mathrm{V}_{\sigma}$ & 0.45 & 0.43 & 0.43 & 0.45 & 0.46 & 0.47 \\
\hline \multirow{3}{*}{20} & $\eta(\%)$ & 89.07 & 89.56 & 89.82 & 89.90 & 90.02 & 90.09 \\
\hline & PCR & 1050.00 & 864.82 & 824.05 & 843.68 & 866.86 & 890.32 \\
\hline & $\mathrm{V}_{\sigma}$ & 0.41 & 0.39 & 0.39 & 0.40 & 0.42 & 0.44 \\
\hline \multirow{3}{*}{22} & $\eta(\%)$ & 88.00 & 89.03 & 89.59 & 89.77 & 89.91 & 90.02 \\
\hline & PCR & 1070.00 & 898.06 & 800.60 & 818.04 & 840.02 & 868.37 \\
\hline & $\mathrm{V}_{\sigma}$ & 0.39 & 0.36 & 0.35 & 0.37 & 0.39 & 0.41 \\
\hline \multirow{3}{*}{24} & $\eta(\%)$ & 86.49 & 87.69 & 88.64 & 89.60 & 89.77 & 89.91 \\
\hline & PCR & 1090.00 & 903.88 & 782.94 & 798.09 & 823.02 & 846.22 \\
\hline & $\mathrm{V}_{\sigma}$ & 0.38 & 0.3 & 0.32 & 0.32 & 0.35 & 0.38 \\
\hline \multirow{3}{*}{26} & $\eta(\%)$ & 84.54 & 86.13 & 87.69 & 88.87 & 89.62 & 89.81 \\
\hline & PCR & 1060.00 & 876.82 & 759.26 & 780.13 & 801.78 & 823.77 \\
\hline & $\mathrm{V}_{\sigma}$ & 0.38 & 0.32 & 0.30 & 0.30 & 0.31 & 0.35 \\
\hline \multirow{3}{*}{28} & $\eta(\%)$ & 82.53 & 84.25 & 86.47 & 87.58 & 88.84 & 89.64 \\
\hline & PCR & 968.15 & 851.38 & 753.77 & 762.26 & 784.89 & 806.82 \\
\hline & $\mathrm{V}_{\sigma}$ & 0.35 & 0.31 & 0.29 & 0.28 & 0.29 & 0.31 \\
\hline
\end{tabular}

\section{Results and Discussion}

In this study, the $17.7 \mathrm{~m}$ SDCR [29] is taken as the research object. To conduct the research effectively, the following boundary conditions are assumed:

(i) The influence of the cloud cover on the system is not considered

(ii) The dish concentrator is in an ideal working condition, and there is no error in the installation, mirror slope, or tracking. The surface of the concentrator is a mirror reflection

(iii) The surface of the quartz window is specular reflection

The parameters of the SDCR system in this study are shown in Table 3. The optical properties of the quartz window are shown in Table 4 [30]. In the table, $n$ is the refractive index of the quartz window, $\rho_{q w}$ is the reflectivity of the quartz window, and $\mathrm{k}_{\lambda}$ is the absorption coefficient of the quartz window. In addition, the structural parameters of the cavity receiver and the quartz window are shown in Section 2.

4.1. Flux Distribution of the Receiver with a Quartz Window. At present, planar quartz windows are widely used in cavity receivers. In this paper, the optical performance of a cavity receiver with a planar quartz window is studied. The diameter of the planar quartz window is $240 \mathrm{~mm}$, and the thickness is $8 \mathrm{~mm}$. The following conclusions are obtained by simulation with the OptisWorks software. The optical efficiency of the cavity receiver is $90.80 \%$. The LCR distribution on the sidewall of the receiver is shown in Figure 5(b). The nonuniformity coefficient of the flux distribution on the sidewall of the receiver is 0.68 , and the peak concentration ratio (PCR) on the sidewall of the receiver is 1320.21 . The results show that the flux distribution of the receiver is highly nonuniform and the PCR is relatively large.

4.1.1. Conical Quartz Window. When a conical quartz window is used in a cavity receiver, there are 36 different structural schemes of the quartz window according to the dimensions $\mathrm{H}_{q w}$ and $\mathrm{D}_{q w}$. The values of dimension $\mathrm{H}_{q w}$ and $\mathrm{D}_{q w}$ of the quartz window refer to Table 1 (the same as below). The results of the optical performance of the receiver obtained by the simulation calculation are shown in Figure 5 and Table 5. As shown in Figure 5(a), the optical efficiency of the receiver using the various quartz window schemes mentioned above is between $87.08 \%$ and $90.08 \%$. The optical efficiency of some of the receivers is greatly reduced due to the total reflection of the solar radiation when it passes through the quartz window. Considering that the optical efficiency is an important factor to measure the optical performance of the receiver, this paper discusses only the optical performance of a quartz window scheme whose optical efficiency is equal to or higher than $89 \%$ (the same as below). Therefore, the optical efficiency of the other quartz window receivers is $89.01-90.10 \%$, which is close to the optical efficiency of the $8 \mathrm{~mm}$ planar quartz window receiver. Figure 5(b) shows the 


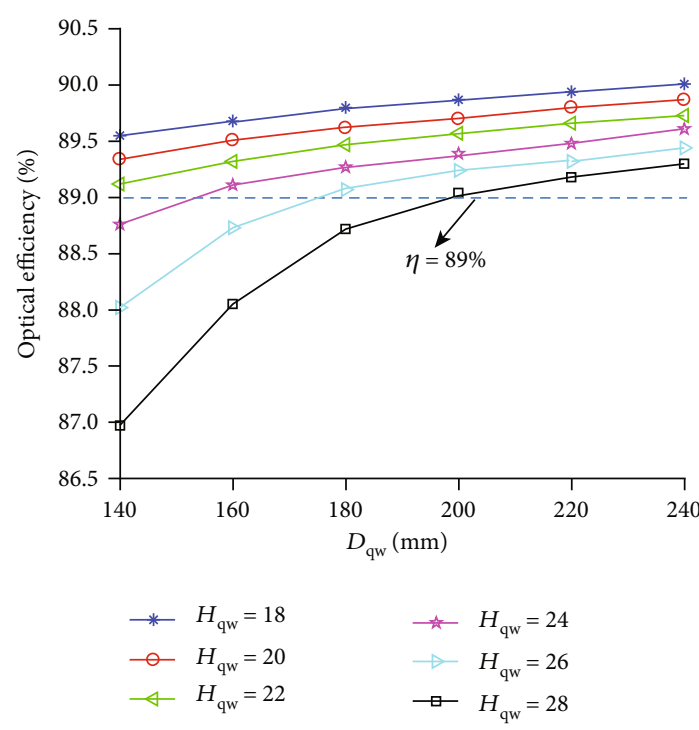

(a)

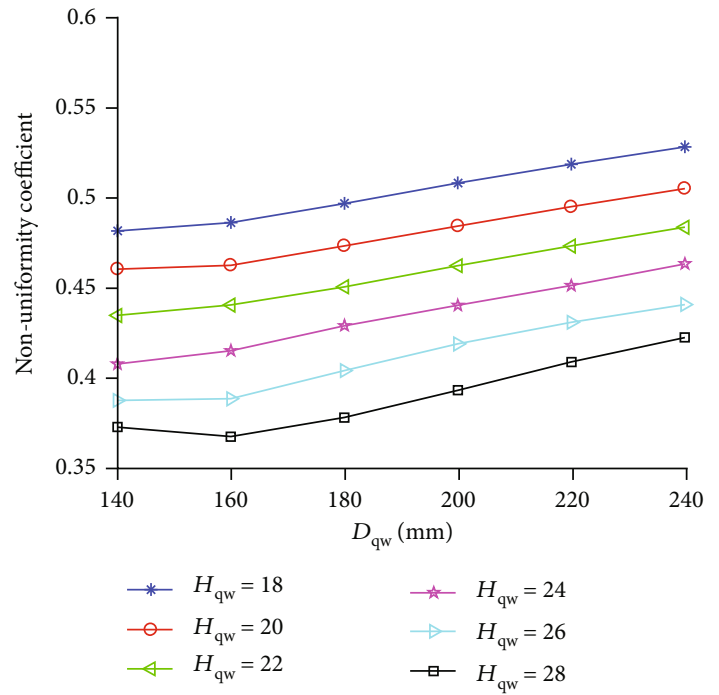

(c)

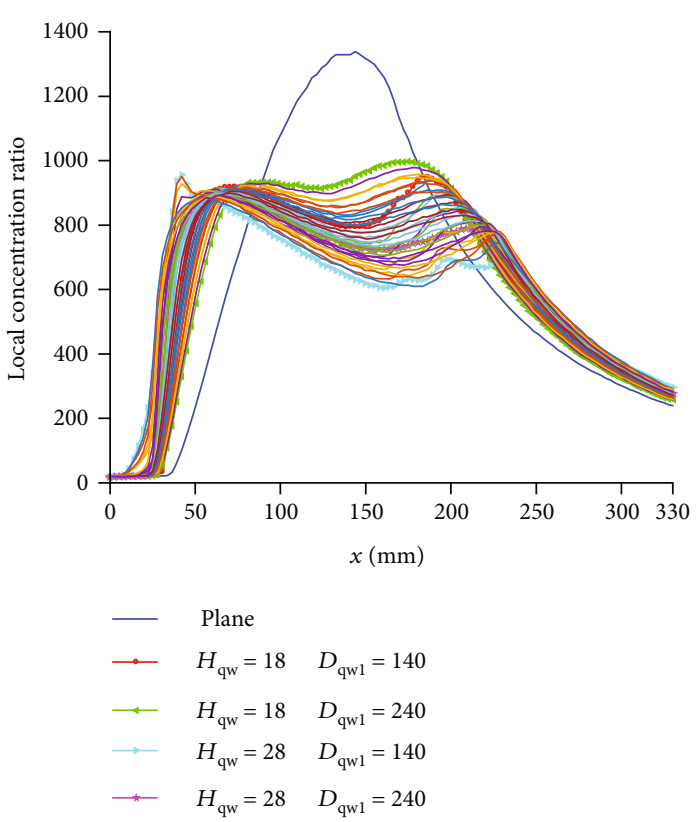

(b)

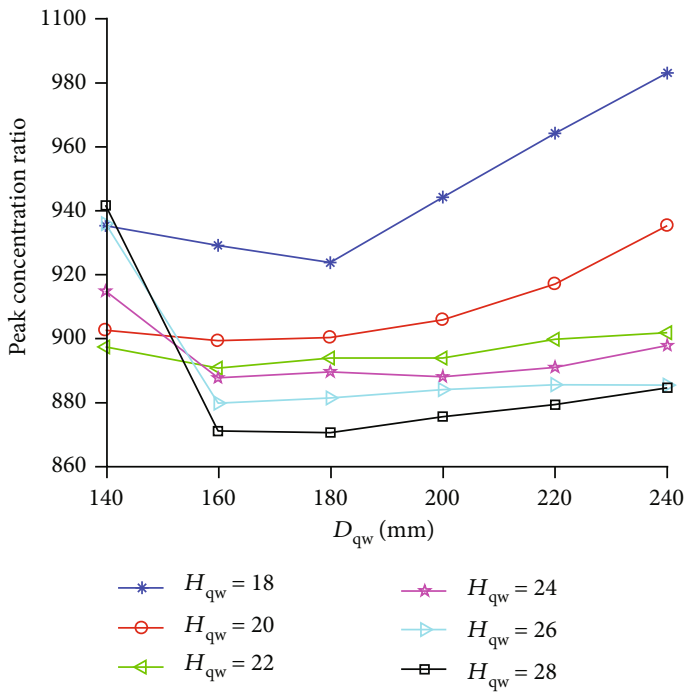

(d)

FIgURE 8: Optical performance of the cylindrical cavity receiver with the hyperbolic tangent quartz window. (a) Optical efficiency. (b) LCR. (c) Nonuniformity coefficient. (d) PCR.

LCR distribution of the receiver's sidewall when a planar quartz window and a conical concave quartz window are used. Considering the large amount of data, only the LCR distribution curve of four extreme working conditions is thickened (the same as in the following sections). It can be seen from the curve in Figure 5(b) that the PCR of the receiver with a conical concave quartz window is much smaller than that with a planar quartz window, and Figure 5(c) shows the nonuniformity coefficient distribution of the receiver sidewall when the conical quartz window is used. It can be seen from Figure 5(c) that the nonuniformity coefficient $\mathrm{V}_{\sigma}$ is between 0.35 and 0.53 ; while keeping $\mathrm{H}_{q w}$ constant, the nonuniformity coefficient $\mathrm{V}_{\sigma}$ monotonically increases, and it is in the range of $22.06-48.53 \%$ and lower than that of the receiver with the $8 \mathrm{~mm}$ planar quartz window receiver. Figure $5(\mathrm{~d})$ shows the PCR on the sidewall of the receiver when the conical quartz window is used. It can be seen from the figure that the value range of the PCR on the receiver is 838.90-997.68. While keeping $\mathrm{H}_{q w}$ constant, the PCR increased monotonically, and it decreased by 24.43$36.46 \%$ compared with the PCR with the $8 \mathrm{~mm}$ planar quartz window receiver. Therefore, in terms of the overall optical performances of the receiver, the conical quartz window is the best when $\mathrm{H}_{q w}$ is $26 \mathrm{~mm}$ and $\mathrm{D}_{q w}$ is $160 \mathrm{~mm}$.

4.1.2. Spherical Quartz Window. When the spherical quartz window is used in the cavity receiver, the results of the optical performance of the receiver obtained by the simulation are 
TABLE 8: Optical performance of the cylindrical cavity receiver with a hyperbolic tangent quartz window.

\begin{tabular}{|c|c|c|c|c|c|c|c|}
\hline \multirow{2}{*}{$\mathrm{H}_{\mathrm{qw}}, \mathrm{mm}$} & \multirow{2}{*}{ Parameters } & \multicolumn{6}{|c|}{$\mathrm{D}_{\mathrm{qw}}, \mathrm{mm}$} \\
\hline & & 140 & 160 & 180 & 200 & 220 & 240 \\
\hline \multirow{3}{*}{18} & $\eta(\%)$ & 89.55 & 89.68 & 89.80 & 89.87 & 89.94 & 90.01 \\
\hline & PCR & 935.45 & 929.29 & 923.92 & 944.31 & 964.25 & 983.03 \\
\hline & $\mathrm{V}_{\sigma}$ & 0.48 & 0.49 & 0.50 & 0.51 & 0.52 & 0.53 \\
\hline \multirow{3}{*}{20} & $\eta(\%)$ & 89.34 & 89.51 & 89.62 & 89.70 & 89.80 & 89.87 \\
\hline & PCR & 902.86 & 899.55 & 900.57 & 906.09 & 917.23 & 935.43 \\
\hline & $\mathrm{V}_{\sigma}$ & 0.46 & 0.46 & 0.47 & 0.48 & 0.49 & 0.50 \\
\hline \multirow{3}{*}{22} & $\eta(\%)$ & 89.12 & 89.32 & 89.47 & 89.57 & 89.66 & 89.73 \\
\hline & PCR & 897.65 & 890.99 & 894.18 & 894.15 & 900.04 & 902.07 \\
\hline & $\mathrm{V}_{\sigma}$ & 0.43 & 0.44 & 0.45 & 0.46 & 0.47 & 0.48 \\
\hline \multirow{3}{*}{24} & $\eta(\%)$ & 88.76 & 89.11 & 89.27 & 89.39 & 89.48 & 89.61 \\
\hline & PCR & 915.02 & 887.99 & 889.89 & 888.34 & 891.25 & 898.07 \\
\hline & $\mathrm{V}_{\sigma}$ & 0.41 & 0.42 & 0.43 & 0.44 & 0.45 & 0.46 \\
\hline \multirow{3}{*}{26} & $\eta(\%)$ & 88.02 & 88.73 & 89.07 & 89.24 & 89.32 & 89.44 \\
\hline & PCR & 936.02 & 880.12 & 881.76 & 884.29 & 885.88 & 885.70 \\
\hline & $\mathrm{V}_{\sigma}$ & 0.39 & 0.39 & 0.40 & 0.41 & 0.43 & 0.44 \\
\hline \multirow{3}{*}{28} & $\eta(\%)$ & 86.97 & 88.05 & 88.72 & 89.04 & 89.18 & 89.30 \\
\hline & PCR & 941.77 & 871.41 & 870.93 & 875.89 & 879.66 & 884.90 \\
\hline & $\mathrm{V}_{\sigma}$ & 0.37 & 0.37 & 0.38 & 0.39 & 0.41 & 0.42 \\
\hline
\end{tabular}

shown in Figure 6 and Table 6. As shown in Figure 6(a), the scheme with the optical efficiency lower than $89 \%$ is first removed. Figure 6(b) shows the LCR distribution of the receiver's sidewall when the planar quartz window and the spherical concave quartz window are used. According to the curve in Figure 6(b), it can be found that the PCR of the receiver with the spherical concave quartz window is much smaller than that of the receiver with the planar quartz window. Figure 6(c) shows the nonuniformity coefficient distribution on the sidewall of the receiver when the spherical quartz window is used. It can be seen from the figure that the nonuniformity coefficient $\mathrm{V}_{\sigma}$ is between 0.36 and 0.55 . While keeping $\mathrm{H}_{q w}$ constant, the nonuniformity coefficient $\mathrm{V}_{\sigma}$ increases monotonically with $\mathrm{D}_{q w}$, and it decreases by $19.12-47.06 \%$ compared with the nonuniformity coefficient of the receiver with the $8 \mathrm{~mm}$ planar quartz window receiver. Figure 6(d) shows the PCR on the sidewall of the receiver when the spherical quartz window is used. It can be seen from the figure that the value range of the receiver PCR is 856.42-1070. While keeping $\mathrm{H}_{q w}$ constant, the PCR increases monotonically with $\mathrm{D}_{q w}$, and it decreases by $18.95-35.13 \%$ compared with the PCR using the $8 \mathrm{~mm}$ planar quartz window receiver. Therefore, in terms of the overall optical performance of the receiver, the spherical quartz window is the best when $\mathrm{H}_{\boldsymbol{q} w}$ is $22 \mathrm{~mm}$ and $\mathrm{D}_{q w 1}$ is $160 \mathrm{~mm}$.

4.1.3. Sinusoidal Quartz Window. When the sinusoidal quartz window is used in the cavity receiver, the results of the optical performance of the receiver obtained by the simulation are shown in Figure 7 and Table 7. As shown in
Figure $7(a)$, the scheme with an optical efficiency lower than $89 \%$ is first removed. Figure 7 (b) shows the LCR distribution of the receiver's sidewall when the planar quartz window and the sinusoidal concave quartz window are used. According to the curve shown in Figure 7(b), it can be found that the PCR of the receiver with the sinusoidal concave quartz window is much smaller than that of the receiver with the planar quartz window. Figure $7(\mathrm{c})$ shows the nonuniformity coefficient distribution on the sidewall of the receiver when the sinusoidal quartz window is used. It can be seen from the figure that the nonuniformity coefficient $\mathrm{V}_{\sigma}$ is between 0.31 and 0.47 , and it decreases by $30.88-54.41 \%$ compared with the nonuniformity coefficient of the receiver with the $8 \mathrm{~mm}$ planar quartz window receiver. Figure $7(\mathrm{~d})$ shows the PCR on the sidewall of the receiver when the spherical quartz window is used. It can be seen from the figure that the value range of the receiver PCR is 798.09-923.42. While keeping $\mathrm{H}_{q w}$ constant, the PCR decreases first and then increases with $\mathrm{D}_{q w}$, and it decreases by $30.06-39.55 \%$ compared with the PCR using the $8 \mathrm{~mm}$ planar quartz window receiver. Therefore, in terms of the overall optical performance of the receiver, the sinusoidal quartz window is the best when $\mathrm{H}_{q w}$ is $28 \mathrm{~mm}$ and $\mathrm{D}_{q w 1}$ is $240 \mathrm{~mm}$.

4.1.4. Hyperbolic Tangent Quartz Window. When the hyperbolic tangent quartz window is used in the cavity receiver, the results of the optical performance of the receiver obtained by the simulation are shown in Figure 8 and Table 8 As shown in Figure 8(a), the scheme with an optical efficiency of lower than $89 \%$ is first removed. Figure $8(\mathrm{~b})$ shows the LCR 
TABLE 9: Optical performance parameters of a cavity receiver with a quartz window with four optimal structure schemes.

\begin{tabular}{|c|c|c|c|c|c|}
\hline Name & $\mathrm{H}_{q w}(\mathrm{~mm})$ & $\mathrm{D}_{q w}(\mathrm{~mm})$ & $\eta(\%)$ & $\mathrm{V}_{\sigma}$ & PCR \\
\hline Receiver with sinusoidal quartz window & 28 & 240 & 89.64 & 0.31 & 806.82 \\
\hline Receiver with conical window & 26 & 160 & 89.09 & 0.35 & 841.31 \\
\hline Receiver with spherical quartz window & 22 & 160 & 89.25 & 0.36 & 853.23 \\
\hline Receiver with hyperbolic tangent quartz window & 28 & 200 & 89.04 & 0.39 & 875.89 \\
\hline
\end{tabular}

distribution of the receiver's sidewall when the planar quartz window and the hyperbolic tangent concave quartz window are used. According to the curve in Figure 8(b), it can be found that the PCR of the receiver with the hyperbolic tangent concave quartz window is much smaller than that of the receiver with the planar quartz window. Figure 8(c) shows the nonuniformity coefficient distribution on the sidewall of the receiver when the hyperbolic tangent quartz window is used. It can be seen from the figure that the nonuniformity coefficient $\mathrm{V}_{\sigma}$ is between 0.39 and 0.53 , and it decreases by $22.06-42.65 \%$ compared with the nonuniformity coefficient of the receiver with an $8 \mathrm{~mm}$ planar quartz window receiver. Figure $8(\mathrm{~d})$ shows the PCR on the sidewall of the receiver when the spherical quartz window is used. It can be seen from the figure that the value range of the receiver PCR is $875.89-983.03$, and it decreases by $25.54-$ $33.66 \%$ compared with the PCR using the $8 \mathrm{~mm}$ planar quartz window receiver. Therefore, in terms of the overall optical performance of the receiver, the hyperbolic tangent quartz window is the best when $\mathrm{H}_{q w}$ is $28 \mathrm{~mm}$ and $\mathrm{D}_{q w 1}$ is $240 \mathrm{~mm}$.

\subsection{Comprehensive Analysis}

4.2.1. Comparison of the Different Designs. According to the calculation results in Section 4.1, when the cavity receiver uses four types of quartz windows with different structures, i.e., conic, spherical, sinusoidal, and hyperbolic tangent, its optical performance is evaluated. The optimal structure schemes of the four types of quartz windows are shown in Table 9, Figure 9 shows the LCR distribution of the receiver sidewall under the four quartz window structure schemes, and Figure 10 shows the LCR distribution of the receiver sidewall under the four quartz window structure schemes. According to Table 9 and Figure 9, further analysis of the quartz windows of the four structural schemes shows that the optical efficiency of all of the structural schemes is basically the same. From the comparison of the nonuniformity coefficient and the peak value of the concentration ratio, it can be found that the optimal optical properties of the four types of quartz windows are sinusoidal, conical, spherical, and hyperbolic tangent quartz windows. The nonuniformity coefficient of the receiver with the sinusoidal quartz window is 0.31 and the PCR is 806.82 .

4.2.2. Influence of the Installation Position of the Cavity Receiver. According to the analysis results in Section 4.2.1, the sinusoidal quartz window receiver with the optimal structure scheme is further discussed, and the quartz window's dimensions are $H_{\mathrm{qw}}=28 \mathrm{~mm}$ and $D_{\mathrm{qw}}=240 \mathrm{~mm}$ when the

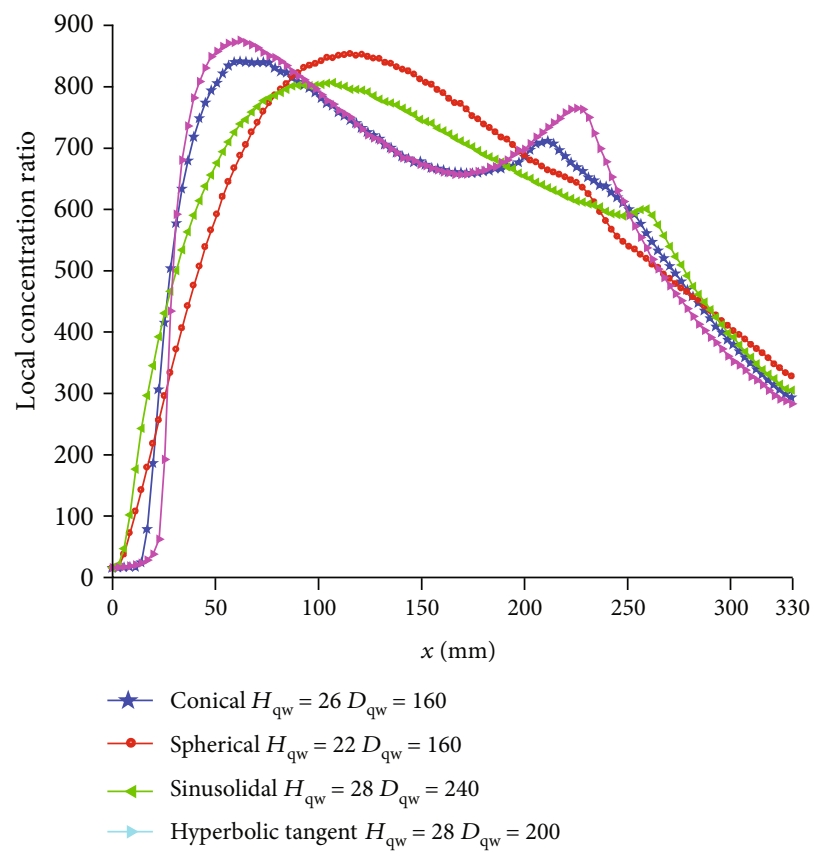

FIGURE 9: LCR distribution of a receiver with a concave quartz window with four optimal structure schemes.

distance $L$ between the apex of the dish concentrator and the point $\mathrm{O}_{q w}$ on the receiver is changed (shown in Figure 1), in other words, when $L=f+0.06 \mathrm{~m}, L=f+$ $0.012 \mathrm{~m}, L=f-0.006 \mathrm{~m}$, and $L=f-0.012 \mathrm{~m}$, respectively. The optical performance of the receiver in these four cases is simulated and calculated, and the results are shown in Table 10 and Figure 11. The results show that the optical efficiency basically remains unchanged when $L$ increases, the nonuniformity coefficient increases, and the PCR increases. When $L$ is equal to $f-0.006 \mathrm{~m}$, the optical efficiency of the receiver basically remains unchanged, but the nonuniformity coefficient drops to 0.31 , and the PCR drops to 766.93. The optical performance of the receiver has been further improved.

4.2.3. Influence of the Absorptivity of the Cavity Receiver Surface. When the new absorptivity $\sigma_{\text {ca }}$ is set to $0.80,0.83$, $0.86,0.89,0.92$, and 0.95 , respectively. The results of the receiver's optical efficiency in six cases are shown in Table 11 and Figure 12. When the absorptivity decreases, the optical efficiency $\eta$ will decrease from 89.64 to 86.94 . This finding is mainly caused by the fact that when the absorptivity decreases, the reflectivity increases, and the solar radiation that enters the receiver cavity will escape more, thus reducing the optical efficiency of the receiver. In addition, although the 


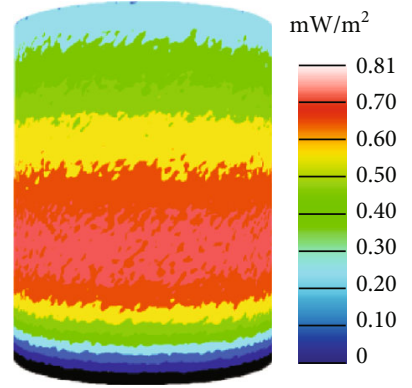

(a)

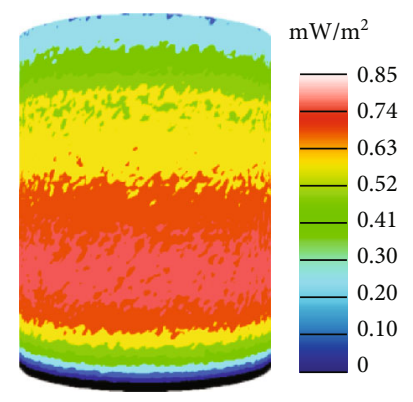

(b)

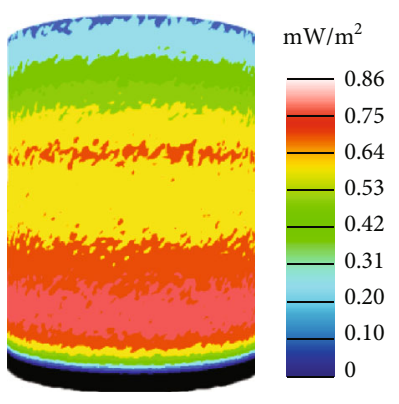

(c)

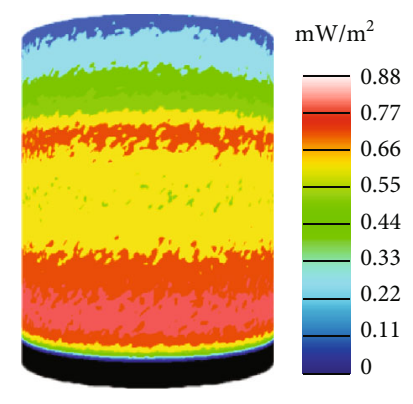

(d)

FIGURE 10: LCR contours of a receiver with a concave quartz window with four optimal structure schemes: (a) sinusoidal, (b) conical, (c) spherical, and (d) hyperbolic tangent.

TABLE 10: Optical performance parameters of the receiver when changing the installation position of the sinusoidal quartz window $\left(\mathrm{H}_{q w}=28 \mathrm{~mm}, \mathrm{D}_{q w}=240 \mathrm{~mm}\right)$.

\begin{tabular}{lccccc}
\hline Parameters & $L=f$ & $L=f+0.06$ & $L=f+0.012$ & $L=f-0.006$ & $2=f-0.012$ \\
\hline$\eta(\%)$ & 89.64 & 89.60 & 89.59 & 89.62 & 89.64 \\
PCR & 806.82 & 854.75 & 909.41 & 766.93 & 737.93 \\
$\mathrm{~V}_{\sigma}$ & 0.31 & 0.38 & 0.34 & 0.31 & 0.33 \\
\hline
\end{tabular}

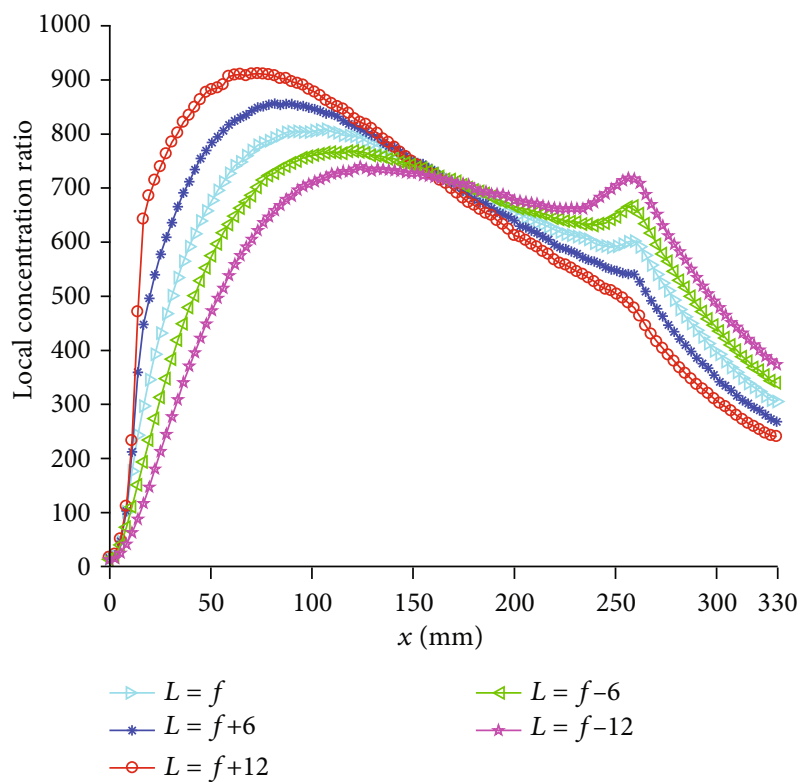

FIGURE 11: LCR distribution of the receiver when changing the installation position of the sinusoidal quartz window $\left(H_{\mathrm{qw}}=28 \mathrm{~mm}, D_{\mathrm{qw}}=240 \mathrm{~mm}\right)$.

decrease of absorptivity will lead to the decrease of the nonuniformity coefficient $\mathrm{V}_{\sigma}$ and PCR, the decrease also comes at the expense of optical efficiency; therefore, the coating of the receiver should be overhauled regularly in real application to ensure its good performance.

4.2.4. Influence of Focal Distance of Parabolic Dish Concentrator. When the radius $\mathrm{R}_{\mathrm{d}}$ of the parabolic dish con- centrator was kept constant, and the focal distance $f$ of the parabolic dish was changed to $8.99 \mathrm{~m}$, it was found from Table 12 and Figure 13 that the PCR of the receiver with concave quartz window was decreased from 1396.6 to 831.57, and the $\mathrm{V}_{\sigma}$ was decreased from 0.70 to 0.34 compared with that of the receiver with plane quartz window. When the focal distance $f$ was $9.99 \mathrm{~m}$, the PCR of the receiver with concave quartz window was decreased from 1237.30 to 788.69 , and the $\mathrm{V}_{\sigma}$ was decreased from 0.66 to 0.33 compared with that of the receiver with plane quartz window. Therefore, for the parabolic dish concentrator with different focal distance, the concave quartz window can also improve the uniformity of the flux distribution of the receiver cylindrical cavity. On the other hand, the parabolic dish with proper focal distance should be used in the SDCR system.

\section{Conclusions}

Four types of concave quartz windows, including conical, spherical, sinusoidal, and hyperbolic tangent, are proposed to be used in the cylindrical cavity receiver. For each concave quartz window, 36 structural schemes are selected. The research shows that the concave quartz window can improve the flux uniformity of the receiver significantly. The specific conclusions of this paper are as follows:

(i) The optical efficiency of the conventional planar quartz window is $90.80 \%$, and the nonuniformity coefficient is 0.68 , while the PCR on the sidewall of the receiver is 1320.21

(ii) The optical properties of the receiver with four different concave quartz windows are evaluated. When $\mathrm{H}_{q w}$ is $28 \mathrm{~mm}$ and $\mathrm{D}_{q w}$ is $240 \mathrm{~mm}$, the sinusoidal 
TABLE 11: Optical performance of the receiver when the absorptivity of the cavity receiver surface is changed.

\begin{tabular}{lcccccc}
\hline Parameters & $\sigma_{\mathrm{ca}}=0.8$ & $\sigma_{\mathrm{ca}}=0.83$ & $\sigma_{\mathrm{ca}}=0.86$ & $\sigma_{\mathrm{ca}}=0.89$ & $\sigma_{\mathrm{ca}}=0.92$ & 88.92 \\
\hline$\eta(\%)$ & 86.94 & 87.46 & 88.00 & 88.49 & $\sigma_{\mathrm{ca}}=0.95$ \\
PCR & 760.30 & 771.03 & 778.01 & 789.30 & 796.38 \\
$\mathrm{~V}_{\sigma}$ & 0.28 & 0.28 & 0.29 & 0.30 & 0.31 & 806.82 \\
\hline
\end{tabular}

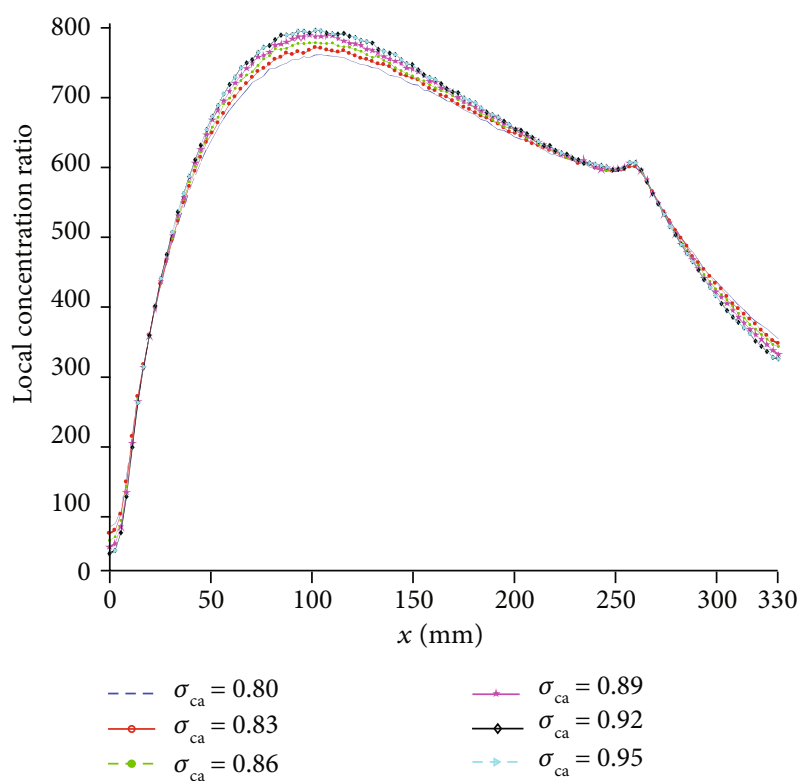

FIGURE 12: LCR distribution of the receiver when the absorptivity of the receiver surface is changed.

TABLE 12: Optical performance parameters of the receiver of parabolic dish concentrator at different focal distances.

\begin{tabular}{lcccc}
\hline$f(\mathrm{~m})$ & $f=8.99$ & $f=8.99$ & $f=9.99$ & $f=9.99$ \\
\hline Quartz window & Plane & Concave & Plane & Concave \\
$\eta(\%)$ & 90.40 & 89.71 & 90.37 & 89.66 \\
PCR & 1396.60 & 831.57 & 1237.30 & 788.69 \\
$\mathrm{~V}_{\sigma}$ & 0.70 & 0.34 & 0.66 & 0.33 \\
\hline
\end{tabular}

quartz window is the best scheme. The optical efficiency of the receiver is $89.04 \%$, which is basically the same as that of the flat quartz window receiver, but the nonuniformity coefficient is reduced to 0.31 , and the PCR is reduced to 806.82

(iii) The other three optimal schemes of the concave quartz windows are the following: when $\mathrm{H}_{q w}$ is $26 \mathrm{~mm}$ and $\mathrm{D}_{q w}$ is $160 \mathrm{~mm}$ for the conical quartz window, the optical efficiency of the receiver is $89.09 \%$, the nonuniformity coefficient is 0.35 , and the value of the PCR is 841.31. When $\mathrm{H}_{q w}$ is $22 \mathrm{~mm}$ and $\mathrm{D}_{q w}$ is $160 \mathrm{~mm}$ for the spherical quartz window, the optical efficiency of the receiver is $89.25 \%$, the nonuniformity coefficient is 0.36 , and the value of the PCR is 853.23 . When $\mathrm{H}_{q w}$ is $28 \mathrm{~mm}$ and $\mathrm{D}_{q w}$ is

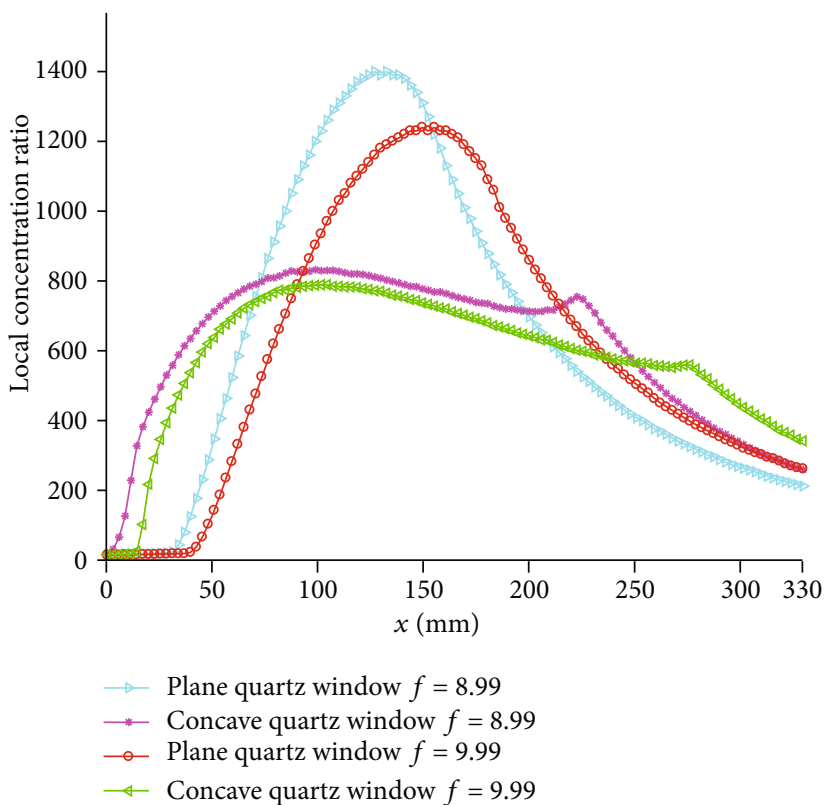

FIgURE 13: LCR distribution of the receiver of parabolic dish concentrator at different focal distances.

$200 \mathrm{~mm}$ for the hyperbolic tangent quartz window, the optical efficiency of the receiver is $89.04 \%$, the nonuniformity coefficient is 0.39 , and the value of the PCR is 875.89

(iv) The receiver of the sinusoidal quartz window $\left(H_{\mathrm{qw}}=28 \mathrm{~mm}, D_{\mathrm{qw}}=240 \mathrm{~mm}\right)$ with the optimal scheme is further discussed and found. When $L=f-0.006 \mathrm{~m}$, the optical efficiency of the receiver basically remains unchanged, but the nonuniformity coefficient drops to 0.31 , and the PCR drops to 766.93. The optical performance of the receiver has been further improved. When the absorptivity of the receiver decreases, the optical efficiency $\eta$ will decrease; therefore, the coating of the receiver should be overhauled regularly in real application to ensure its good performance. For the parabolic dish concentrator with different focal distance, the concave quartz window can also improve the uniformity of the flux distribution of the cylindrical cavity receiver

\section{Nomenclature}

$\mathrm{R}_{d}: \quad$ Aperture radius of the dish concentrator, $\mathrm{m}$

$f$ : $\quad$ Focal length of the dish concentrator, $m$

$\mathrm{H}_{\mathrm{qw}}$ : Thickness at the edge of the quartz window, $\mathrm{m}$ 
$\mathrm{D}_{\mathrm{qw}}$ : Diameter of the concave surface of the quartz window, $m$

L: $\quad$ Distance between the dish concentrator and receiver, $m$

$\mathrm{W}_{\boldsymbol{0}}$ : The value of the solar direct normal irradiance, $\mathrm{W} / \mathrm{m}^{2}$

$\mathrm{E}_{c a}$ : Total energy absorbed by the receiver, $\mathrm{W}$

$E_{\text {average }}$ : Average value of the flux distribution of the receiver

$\mathrm{n}$ : Refractive index of the quartz window

$\mathrm{k}_{\lambda}$ : Absorption coefficient of the quartz window, $\mathrm{m}^{-1}$

$\mathrm{C}_{\mathrm{i}}$ : $\quad$ The value of the local concentration ratio

$\mathrm{V}_{\sigma}$ : Nonuniformity coefficient.

\section{Greek Symbols}

$\delta: \quad$ Solar half angle, $\delta=4.65 \mathrm{mrad}$

$\rho_{\mathrm{d}}$ : Reflectivity of the dish concentrator surface

$\rho_{\mathrm{qw}}$ : Reflectivity of the quartz window

$\sigma_{\text {ca }}$ : Absorptivity of the cavity receiver surface

$\rho_{\text {ca }}:$ Reflectivity of the cavity receiver surface

$\eta$ : Optical efficiency of the cavity receiver

$\phi_{\text {rim }}$ : Rim angle of the dish concentrator, degrees

$\lambda$ : Wavelength, $\mu \mathrm{m}$.

\section{Subscripts}

qw: Quartz windows

d: Dish concentrator

ca: Cavity solar receiver.

\section{Abbreviations}

DNI: Solar direct normal irradiation, $\mathrm{W} / \mathrm{m}^{2}$

MCRT: Monte Carlo ray-tracing method

LCR: Local concentration ratio

PCR: Peak concentration ratio

SDCR: Solar dish concentrator/cavity receiver system.

\section{Data Availability}

The data used to support the findings of this study are available from the corresponding author upon request.

\section{Conflicts of Interest}

The authors declare that there are no conflicts of interest regarding the publication of this paper.

\section{Acknowledgments}

This work is supported by the Hunan Province Natural Science Foundation of China (No. 2019JJ50202, 2019JJ40085), Hunan Provincial Department of Education Scientific Research Foundation of China (No. 18B565, 19C0794), National Natural Science Foundation of China (No. 51641504), and Hunan Vocational College of Science and Technology Scientific Research Project of China (No. KJ18103).

\section{References}

[1] M. S. Guney, "Solar power and application methods," Renewable and Sustainable Energy Reviews, vol. 57, pp. 776-785, 2016.

[2] H. Wang, J. Huang, M. Song, and J. Yan, "Effects of receiver parameters on the optical performance of a fixed-focus Fresnel lens solar concentrator/cavity receiver system in solar cooker," Applied Energy, vol. 237, pp. 70-82, 2019.

[3] A. Z. Hafez, A. Soliman, K. A. el-Metwally, and I. M. Ismail, "Design analysis factors and specifications of solar dish technologies for different systems and applications," Renewable and Sustainable Energy Reviews, vol. 67, pp. 1019-1036, 2017.

[4] Y. L. He, B. C. Du, K. Wang, Y. Qiu, and Z. B. Liu, "Study on the coupled photon-thermal-stress integration method, characteristics with time and failure criterion in the solar molten salt cavity receiver," Chinese Science Bulletin, vol. 62, no. 36, pp. 4307-4320, 2017.

[5] Y. L. He, F. Q. Cui, Z. D. Cheng, Z. Y. Li, and W. Q. Tao, "Numerical simulation of solar radiation transmission process for the solar tower power plant: from the heliostat field to the pressurized volumetric receiver," Applied Thermal Engineering, vol. 61, no. 2, pp. 583-595, 2013.

[6] M. Röger, M. Pfänder, and R. Buck, "Multiple air-jet window cooling for high-temperature pressurized volumetric receivers: testing, evaluation, and modeling," Journal of Solar Energy Engineering, vol. 128, no. 3, pp. 265-274, 2006.

[7] M. H. Tan, K. K. Chong, and C. W. Wong, "Optical characterization of nonimaging dish concentrator for the application of dense-array concentrator photovoltaic system," Applied Optics, vol. 53, no. 3, pp. 475-486, 2014.

[8] K. K. Chong, F. L. Siaw, C. W. Wong, and G. S. Wong, "Design and construction of non-imaging planar concentrator for concentrator photovoltaic system," Renewable Energy, vol. 34, no. 5, pp. 1364-1370, 2009.

[9] J. Yan, Y. D. Peng, and Z. R. Cheng, "Optimization of a discrete dish concentrator for uniform flux distribution on the cavity receiver of solar concentrator system," Renewable Energy, vol. 129, pp. 431-445, 2018.

[10] J. Yan, Y. D. Peng, and Z. R. Cheng, "Mirror rearrangement optimization for uniform flux distribution on the cavity receiver of solar parabolic dish concentrator system," International Journal of Energy Research, vol. 42, no. 11, pp. 35883614, 2018.

[11] E. Bellos, E. Bousi, C. Tzivanidis, and S. Pavlovic, "Optical and thermal analysis of different cavity receiver designs for solar dish concentrators," Energy Conversion and Management, vol. 2, article 100013, 2019.

[12] Y. Shuai, X. L. Xia, and H. P. Tan, "Radiation performance of dish solar concentrator/cavity receiver systems," Solar Energy, vol. 82, no. 1, pp. 13-21, 2008

[13] Y. Jin, J. Fang, J. Wei, M. A. Qaisrani, and X. Wang, "Thermal performance evaluation of a cavity receiver based on particle's radiation properties during the day time," Renewable Energy, vol. 143, pp. 622-636, 2019.

[14] Y. B. Tao, Y. L. He, F. Q. Cui, and C. H. Lin, "Numerical study on coupling phase change heat transfer performance of solar dish collector," Solar Energy, vol. 90, pp. 84-93, 2013.

[15] A. Kribus, P. Doron, R. Rubin et al., "A multistage solar receiver:: the route to high temperature," Solar Energy, vol. 67, no. 1-3, pp. 3-11, 1999. 
[16] P. Furler and A. Steinfeld, "Heat transfer and fluid flow analysis of a $4 \mathrm{~kW}$ solar thermochemical reactor for ceria redox cycling," Chemical Engineering Science, vol. 137, pp. 373-383, 2015.

[17] A. Kribus, P. Doron, R. Rubin et al., "Performance of the directly-irradiated annular pressurized receiver (DIAPR) operating at 20 bar and $1,200^{\circ} \mathrm{C}$," Journal of Solar Energy Engineering, vol. 123, no. 1, pp. 10-17, 2001.

[18] F. Cui, Y. He, Z. Cheng, and Y. Li, "Study on combined heat loss of a dish receiver with quartz glass cover," Applied Energy, vol. 112, pp. 690-696, 2013.

[19] D. Hirsch and A. Steinfeld, "Solar hydrogen production by thermal decomposition of natural gas using a vortex-flow reactor," International Journal of Hydrogen Energy, vol. 29, no. 1, pp. 47-55, 2004.

[20] P. Heller, M. Pfänder, T. Denk et al., "Test and evaluation of a solar powered gas turbine system," Solar Energy, vol. 80, no. 10, pp. 1225-1230, 2006.

[21] R. Buck, T. Bra“uning, T. Denk, M. Pfa“nder, P. Schwarzbo“zl, and F. Tellez, "Solar-hybrid gas turbine-based power tower systems (REFOS)," Journal of Solar Energy Engineering, vol. 124, no. 1, pp. 2-9, 2002.

[22] B. C. Du, Y. Qiu, Y. L. He, and X. D. Xue, "Study on heat transfer and stress characteristics of the pressurized volumetric receiver in solar power tower system," Applied Thermal Engineering, vol. 133, pp. 341-350, 2018.

[23] S. Yong, W. Fu-Qiang, X. Xin-Lin, T. He-Ping, and L. YingChun, "Radiative properties of a solar cavity receiver/reactor with quartz window," International Journal of Hydrogen Energy, vol. 36, no. 19, pp. 12148-12158, 2011.

[24] A. M. Daabo, S. Mahmoud, and R. K. Al-Dadah, “The optical efficiency of three different geometries of a small scale cavity receiver for concentrated solar applications," Applied Energy, vol. 179, pp. 1081-1096, 2016.

[25] J. Yan, Z. R. Cheng, and Y. D. Peng, "Effects of geometrical parameters of a dish concentrator on the optical performance of a cavity receiver in a solar dish-Stirling system," International Journal of Energy Research, vol. 42, no. 6, pp. 21522168, 2018.

[26] D. Xie, Y. Wang, H. Wang, S. Mo, and M. Liao, "Numerical analysis of temperature non-uniformity and cooling capacity for capillary ceiling radiant cooling panel," Renewable Energy, vol. 87, pp. 1154-1161, 2016.

[27] S. M. Jeter, "The distribution of concentrated solar radiation in paraboloidal collectors," Journal of Solar Energy Engineering, vol. 108, no. 3, pp. 219-225, 1986.

[28] Y. Z. Zhao and H. R. Yin, Glass technology, Chemical Industry Press, Beijing, China, 2006.

[29] J. Yan, Z. R. Cheng, and Y. D. Peng, "Effect of tracking error of double-axis tracking device on the optical performance of solar dish concentrator," International Journal of Photoenergy, vol. 2018, Article ID 9046127, 13 pages, 2018.

[30] X. Chen, X. L. Xia, X. H. Dong, and G. L. Dai, "Integrated analysis on the volumetric absorption characteristics and optical performance for a porous media receiver," Energy Conversion and Management, vol. 105, pp. 562-569, 2015. 